\title{
Identification of key pathways and gene changes in primary pancreatic stellate cells after cross-talk with pancreatic cancer cells (BXPC-3) using bioinformatics analysis
}

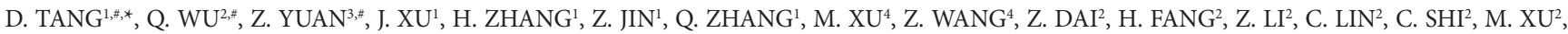
X. SUN ${ }^{2}$, D. WANG ${ }^{1, *}$

${ }^{1}$ Department of General Surgery, Institute of General Surgery, Clinical Medical College, Yangzhou University (Northern Jiangsu People's Hospital), Yangzhou, China; ${ }^{2}$ Medical College of Yangzhou University, Yangzhou, China; ${ }^{3}$ Department of General Surgery, Anhui no. 2 Provincial People's Hospital, Hefei, China; 4Department of General Surgery, The First Affiliated Hospital of Nanjing Medical University, Nanjing, China

*Correspondence: 83392785@qq.com, daorong666@sina.com

${ }^{*}$ Contributed equally to this work.

Received September 25, 2018 / Accepted December 19, 2018

\begin{abstract}
It is well known that as the king of cancer, pancreatic ductal adenocarcinoma (PDAC) has malignant biological behavior and poor prognosis. The interaction between pancreatic stellate cells and PDAC cells promotes PDAC development. The aim of this study was to describe gene characteristics in pancreatic stellate cell (PSCs) after cross-talk with BXPC-3 and unravel their underlying mechanisms. The expression profiling analysis of genes in PSCs was performed after $48 \mathrm{~h}$ co-culture with primary BXPC-3. The Kyoto Encyclopedia of Genes and Genomes pathway (KEGG) enrichment analysis and gene ontology (GO) analysis were performed and the differentially expressed genes (DEGs) were identified by Agilent GeneSpring GX program. In total, 1804 DEGs were filtered out in PSCs, including 958 up-regulated genes and 846 down-regulated genes. GO analysis showed that the up-regulated DEGs were significantly enriched in biological processes (BP) such as defense response, immune system processes and immune response, while the down-regulated DEGs were significantly enriched in biological regulation and cytoskeleton organization. KEGG pathway analysis showed that 28 pathways were up-regulated and 5 were down-regulated. By constructing PPI network, we selected 10 key genes (IL6, IL8, IL1B, BCL2, CCL2, CSF2, KIT, ICAM1, PTPRC and IGF1) and significantly enriched pathways. In conclusion, the current study suggests that the filtered DEGs contribute to our understanding of the molecular mechanisms underlying the interaction between PSCs and pancreatic cancer cells, and might be used as molecular targets to further the study the role of tumor microenvironment in the PDAC progression.
\end{abstract}

Key words: bioinformatics analysis, pancreatic ductal adenocarcinoma (PDAC), pancreatic stellate cell (PSCs), differentially expressed genes (DEGs)

Pancreatic ductal adenocarcinoma (PDAC), one of today's deadliest diseases, ranks fourth in cancer-related deaths, with a median survival time of about six months and a five-year survival rate of less than five percent [1]. Aggressive growth and rapid distant metastasis contribute to a poor prognosis of PDAC. In addition, its low surgical resection rate and its resistance to radiotherapy and chemotherapy lead to extremely difficult treatment [2]. The dense fibrous tissue surrounding PDAC is the main obstacle to drug delivery to the tumor bed, and it plays an important role in the occurrence of tumors [3]. One of the cellular components that contribute to fibromatrix formation is activated PSC $[4,5]$. There is growing evidence that the interactions between PSC and PDAC cells play an important role in the development of PDAC. By producing high levels of cytokines, chemokines, growth factors and large amounts of ECM, PSC creates a microenvironment of fibrosis and hypoxia, which is conducive to the occurrence, development, immune tolerance, invasion, metastasis and resistance to radiation and chemotherapy in PDAC [6-11]. Therefore, targeted therapy for PSC and PDAC cell interaction, especially for PSC in the microenvironment of pancreatic tumors, may become a new therapy for advanced PDAC $[2,12,13]$. There is continuing evidence that multiple genes and cellular signaling pathways are involved in the interac- 
tion between activated PSCs and PDAC cells[14]. Therefore, understanding the molecular mechanism involved in the interaction between PSCs and PDAC cells is extremely important for the development of more effective diagnostic and therapeutic strategies for PDAC.

PDAC cells have a profound influence in boosting PSC activation, proliferation, migration and production of ECM proteins via a paracrine pathway. At the same time, activated PSC can also produce a series of cytokines and extracellular matrix proteins, thereby promoting the formation of microenvironment conducive to tumor development and promoting the survival, proliferation and anti-chemotherapy characteristics of PDAC cells [15]. Therefore, there is a mutual support or "symbiosis" relationship between PSCs and PDAC cells. Increasing evidences indicated that activated PSCs had established a vital role in the progression of PDAC cells, but on the contrast there are little studies keen on the roles of PDAC cells contribute to the development of PSCs. In the independent study, the DEGs and the special signaling pathway of the interaction between PDAC cells and PSCs showed relatively limited degree of overlap. Currently, there is no reliable biomarker profile to identify the effect of PDAC cells on PSCs. For this reason, the interactions among DEGs, especially the signaling pathways between PDAC cells and PSCs, remain to be clarified.

In the current research, we performed the gene expression profiling analysis of primary PSCs co-cultured with or without BXPC-3. Afterwards, the DEGs were identified by Gene-Spring program, followed by GO and KEGG pathway analysis. By analyzing their biological functions and related pathways, we can further understand the development process of PDAC and explore potential biomarkers that can be used as diagnostic, prognostic, and drug targets. These identified pathways, some of which had not been previously studied in the interaction between PSCs and PDAC cells, were worth of further selection and validation.

\section{Materials and methods}

Cells, culture conditions and RNA extraction. The primary human PSCs isolation, identification, maintenance were described as previously $[11,16,17]$. PSCs of passage numbers 2 5 were adopted for all experiments. Pancreatic cancer cell lines (BxPC-3) was grown in DMEM with 10\% FBS. Co-culture experiment is as follows: monolayer of primary PSC $\left(1 \times 10^{5}\right.$ cells $)$ co-cultured with BxPC- 3 cell $\left(5 \times 10^{5}\right.$ cells $)$ in upper and lower of the trans-well (six-well) at $37^{\circ} \mathrm{C}$ for $48 \mathrm{~h}$, separately. After co-culture, the primary human PSC cells were then collected. Total RNA was extracted from harvested cells using Trizol reagent (Invitrogen, Beijing, China). RNA quality and quantity were measured by NanoDrop ND-1000. RNA integrity was evaluated by standard denaturing agarose gel electrophoresis.

DNA microarray. The Human 12 x 135K Gene Expression Array was manufactured by Roche NimbleGen. And
30080 genes were collected from the authoritative data source including NCBI.

RNA labeling and array hybridization. Invitrogen SuperScript ds-cDNA synthesis kit was used to synthesize Doublestrand cDNA (ds-cDNA) in the presence of 100 pmol oligo dT primers. We use NimbleGen Gene Expression Analysis protocol (NimbleGen Systems, Inc., Madison, WI, USA) to clean and label ds-cDNA. And isopropanol/ethanol precipitation was used to purify processed ds-cDNA. The hybridization of microarrays was performed at $42^{\circ} \mathrm{C}$ for $16 \sim 20$ hours using $4 \mu \mathrm{g}$ of $\mathrm{Cy} 3$ labelled ds-cDNA in a hybridization chamber (Hybridization System - NimbleGen Systems, Inc., Madison, WI, USA). Then, we used the Axon GenePix 4000B microarray scanner to scan the slides.

Data collection and identification of DEGs. Axon GenePix 4000B scanner (Molecular Devices Corporation) was used to scan slides at $5 \mu \mathrm{m} /$ pixel resolution by GenePix Pro 6.0 software (Axon). The processed image (TIFF format) were then introduced into NimbleScan software (version 2.5) for expression data analysis and grid alignment. Expression data was normalized through Robust Multichip Average (RMA) algorithm and the quantile normalization in the NimbleScan software. Gene level information was introduced into Agilent GeneSpring GX software for further research. Differentially expressed genes (DEGs) were selected by Fold Change, and we utilized the t-test to screen DEGs with the difference $\geq 2$ fold and defined a $p$-value cutoff of $<0.05$ to be statistically significant. Hierarchical clustering was implemented using the Agilent GeneSpring GX software (version 11.5.1). Pathway and GO analysis were achieved via the standard enrichment computation method. There were three samples in each co-culture group and separate culture group, and we randomly selected one sample for each group to display the result of gene expression profiling.

Gene ontology and pathway enrichment analysis of DEGs. Gene ontology analysis (GO) (http://www.geneontology.org) was performed to classify genes into stratified categories and display the regulatory network of genes [18, 19]. KEGG (http://www.genome.jp) is an information base for systematic analysis of the functions of genes and gene sets, connecting genomic information with higher-order functional information [20]. Generally, mapping target genes to the related annotation in the DAVID database (https://david.ncifcrf.gov) is an crucial foundation for the accomplishment of any high-throughput gene functional analysis [21]. In order to analyze the DEGs at the functional level, we performed KEGG pathway analysis and GO enrichment by DAVID online tool. To be exact, chi-square test and the two-sided Fisher's exact test were applied to range the enrichment level of the pathway category, and the false discovery rate (FDR) was figured to correct the p-value. We chose only pathways that had a $\mathrm{p}$-value of $<0.01$ and an FDR of $<0.01$.

Integration of protein-protein interaction network and module analysis. Search Tool for the Retrieval of Inter- 
acting Genes (STRING version 10.5) database was applied to assess the protein-protein interaction (PPI) network [22]. We imported the DEGs to STRING to assess the interaction and potential functions of the DEGs. We set combined sore $>0.4$ as significant and the selected data was introduced to opensource Cytoscape software. This powerful tool can visualize complex PPI networks and perform relative analysis (http:// cytoscape.org) [23]. The plug-in MCODE and CytoNCA were applied to build the modules of the PPI network and explore key genes in the PPI network. Also, we carried out functional and pathway enrichment analysis on the modules.

The survival analysis of hub genes. The Kaplan-Meier plotter (KM plotter, http://kmplot.com/analysis) was applied to evaluate the prognosis of patients with PDAC. We analyzed the effects of hub genes with high or low levels of mRNA expression on patients' overall survival (OS). The hazard ratio (HR) with 95\% confidence intervals and log rank $\mathrm{p}$-values were calculated.

\section{Results}

Identification of DEGs. The series from each chip was analyzed independently by GeneSpring software and then the DEG list was identified. On the basis of the GeneSpring analysis, combining $\mathrm{p}<0.05$ and fold control $(\mathrm{FC}) \geq 2.0$ criteria, a total of 1804 genes were selected out and 958 of them were up-regulated and 846 of them were downregulated. The top 10 up-regulated genes, C3, IL8, CXCL2, OAS1, CXCL1, PTGS2, CXCL3, IL1B, CXCL6 and CXCL5, and the top 10 down-regulated genes, ALAS2, PTPRZ1, ADH1A, TRIO, SLC4A1, SESN3, BTAF1, NFATC1, DEGS1 and PNPO were identified as well (Table 1). The Boxplot, scatterplot and DEGs expression heat map are displayed in Figure 1, which were all performed based on the all the genes collected (30080 genes).

GO term enrichment analysis. We introduced all DEGs to DAVID to find significant GO categories and pathways.

Table 1. Top 10 upregulated and downregulated DEGs in primary PSCs after cross-talked with BXPC-3.

\begin{tabular}{|c|c|c|c|c|}
\hline SEQ_ID & Gene ID & Gene name & Description & GO biological process \\
\hline \multicolumn{5}{|c|}{ Top 10 upregulated genes } \\
\hline NM_000064 & 718 & $\mathrm{C} 3$ & complement component 3 & GO:0006954(inflammatory response) \\
\hline NM_000584 & 3576 & IL8 & interleukin 8 & GO:0001525(angiogenesis) \\
\hline BC015753 & 2920 & CXCL2 & chemokine (C-X-C motif) ligand 2 & GO:0006935(chemotaxis) \\
\hline NM_002534 & 4938 & OAS1 & $2,5^{\prime}$-oligoadenylate synthetase $1,40 / 46 \mathrm{kDa}$ & GO:0006955(immune response) \\
\hline NM_001511 & 2919 & CXCL1 & $\begin{array}{l}\text { chemokine (C-X-C motif) ligand } 1 \text { (melanoma growth } \\
\text { stimulating activity, alpha) }\end{array}$ & GO:0006935(chemotaxis) \\
\hline NM_000963 & 5743 & PTGS2 & $\begin{array}{l}\text { prostaglandin-endoperoxide synthase } 2 \text { (prostaglandin } \\
\text { G/H synthase and cyclooxygenase) }\end{array}$ & $\begin{array}{l}\text { GO:0001516(prostaglandin biosynthetic } \\
\text { process) }\end{array}$ \\
\hline NM_002090 & 2921 & CXCL3 & chemokine (C-X-C motif) ligand 3 & GO:0006935(chemotaxis) \\
\hline NM_000576 & 3553 & IL1B & interleukin 1 , beta & $\begin{array}{l}\text { GO:0000074(regulation of progression through } \\
\text { cell cycle) }\end{array}$ \\
\hline NM_002993 & 6372 & CXCL6 & $\begin{array}{l}\text { chemokine (C-X-C motif) ligand } 6 \text { (granulocyte chemotac- } \\
\text { tic protein 2) }\end{array}$ & $\begin{array}{l}\text { GO:0006278(RNA-dependent DNA replica- } \\
\text { tion) }\end{array}$ \\
\hline BC008376 & 6374 & CXCL5 & chemokine (C-X-C motif) ligand 5 & GO:0007267(cell-cell signaling) \\
\hline \multicolumn{5}{|c|}{ Top 10 down-regulated genes } \\
\hline NM_000032 & 212 & ALAS2 & $\begin{array}{l}\text { aminolevulinate, delta-, synthase } 2 \text { (sideroblastic/hypo- } \\
\text { chromic anemia) }\end{array}$ & GO:0001666(response to hypoxia) \\
\hline NM_002851 & 5803 & PTPRZ1 & $\begin{array}{l}\text { protein tyrosine phosphatase, receptor-type, } Z \text { polypeptide } \\
1\end{array}$ & $\begin{array}{l}\text { GO:0006470(protein amino acid dephosphory- } \\
\text { lation) }\end{array}$ \\
\hline BC074738 & 124 & ADH1A & alcohol dehydrogenase 1A (class I), alpha polypeptide & GO:0006066(alcohol metabolic process) \\
\hline AK131423 & 7204 & TRIO & triple functional domain (PTPRF interacting) & $\begin{array}{l}\text { GO:0006468(protein amino acid phosphoryla- } \\
\text { tion) }\end{array}$ \\
\hline NM_000342 & 6521 & SLC4A1 & $\begin{array}{l}\text { solute carrier family } 4 \text {, anion exchanger, member } 1 \text { (eryth- } \\
\text { rocyte membrane protein band } 3 \text {, Diego blood group) }\end{array}$ & GO:0006820(anion transport) \\
\hline NM_144665 & 143686 & SESN3 & sestrin 3 & GO:0007050(cell cycle arrest) \\
\hline BC112201 & 9044 & BTAF1 & $\begin{array}{l}\text { BTAF1 RNA polymerase II, B-TFIID transcription factor- } \\
\text { associated, } 170 \mathrm{kDa} \text { (Mot1 homolog, S. cerevisiae) }\end{array}$ & $\begin{array}{l}\text { GO:0016481(negative regulation of transcrip- } \\
\text { tion) }\end{array}$ \\
\hline NM_006162 & 4772 & NFATC1 & $\begin{array}{l}\text { nuclear factor of activated T-cells, cytoplasmic, calcineurin- } \\
\text { dependent } 1\end{array}$ & $\begin{array}{l}\text { GO:0001837(epithelial to mesenchymal transi- } \\
\text { tion); }\end{array}$ \\
\hline NM_003676 & 8560 & DEGS1 & $\begin{array}{l}\text { degenerative spermatocyte homolog } 1 \text {, lipid desaturase } \\
\text { (Drosophila) }\end{array}$ & GO:0006629(lipid metabolic process) \\
\hline NM_018129 & 55163 & PNPO & pyridoxine 5 '-phosphate oxidase & GO:0008615(pyridoxine biosynthetic process) \\
\hline
\end{tabular}

SEQ_ID: NCBI Reference Sequence ID; GENE_ID: GENE_ID in NCBI. 
For biological process (BP), GO analysis result shown that up-regulated DEGs were significantly enriched in defense response, immune system process and immune response, and the down-regulated DEGs were significantly enriched in biological regulation, cytoskeleton organization and regulation of biological process (Table 2). As for molecular function $(\mathrm{MF})$, the upregulated DEGs were enriched in cytokine activity, receptor binding and cytokine receptor binding; the down-regulated DEGs were enriched in phospholipidtranslocating ATPase activity, protein binding and zinc ion binding (Table 2). Also, cell component (CC) analysis showed that the up-regulated DEGs were mainly enriched in extracellular space and extracellular region part; the downregulated DEGs enriched in cortical cytoskeleton and micro-

Table 2. Gene ontology analysis of DEGs in primary PSCs after cross-talked with BXPC-3 (Dif gene Sig GO).

\begin{tabular}{|c|c|c|c|c|}
\hline GO.ID & Term/gene function & Enrichment.Score & p-value & FDR \\
\hline \multicolumn{5}{|c|}{ Up-regulated GOTERM - BP } \\
\hline GO:0006952 & defense response & 23.01810527 & $9.59168 \mathrm{E}-24$ & $3.76857 \mathrm{E}-20$ \\
\hline GO:0002376 & immune system process & 21.85730039 & $1.38899 \mathrm{E}-22$ & $2.72867 \mathrm{E}-19$ \\
\hline GO:0006955 & immune response & 20.3527441 & $4.4387 \mathrm{E}-21$ & $5.81322 \mathrm{E}-18$ \\
\hline GO:0051707 & response to other organism & 15.66196743 & $2.17787 \mathrm{E}-16$ & $2.13922 \mathrm{E}-13$ \\
\hline GO:0006950 & response to stress & 15.320219 & $4.784 E-16$ & $3.759 E-13$ \\
\hline GO:0009607 & response to biotic stimulus & 14.63818369 & $2.30047 \mathrm{E}-15$ & $1.50642 \mathrm{E}-12$ \\
\hline GO:0009617 & response to bacterium & 12.1081803 & $7.79506 \mathrm{E}-13$ & $4.37526 \mathrm{E}-10$ \\
\hline GO:0034097 & response to cytokine stimulus & 11.73590879 & $1.83692 \mathrm{E}-12$ & $9.02159 \mathrm{E}-10$ \\
\hline GO:0002682 & regulation of immune system process & 11.68430905 & $2.06867 \mathrm{E}-12$ & $9.03089 \mathrm{E}-10$ \\
\hline GO:0002237 & response to molecule of bacterial origin & 11.28834605 & $5.14818 \mathrm{E}-12$ & $1.87494 \mathrm{E}-09$ \\
\hline \multicolumn{5}{|c|}{ Up-regulated GOTERM - MF } \\
\hline GO:0005125 & cytokine activity & 11.008952 & $9.796 \mathrm{E}-12$ & $8.914 \mathrm{E}-09$ \\
\hline GO:0005102 & receptor binding & 7.2738898 & $5.322 \mathrm{E}-08$ & $2.422 \mathrm{E}-05$ \\
\hline GO:0005126 & cytokine receptor binding & 6.31954009 & 4.79137E-07 & 0.000145338 \\
\hline GO:0008009 & chemokine activity & 5.4435591 & $3.601 \mathrm{E}-06$ & 0.0008193 \\
\hline GO:0042379 & chemokine receptor binding & 4.856842858 & $1.39046 \mathrm{E}-05$ & 0.002530629 \\
\hline GO:0008083 & growth factor activity & 4.481755514 & $3.29795 \mathrm{E}-05$ & 0.005001896 \\
\hline GO:0019864 & IgG binding & 4.0276789 & $9.383 \mathrm{E}-05$ & 0.0121973 \\
\hline GO:0070851 & growth factor receptor binding & 3.277517847 & 0.000527816 & 0.060039015 \\
\hline GO:0004725 & protein tyrosine phosphatase activity & 3.226329978 & 0.000593841 & 0.060043902 \\
\hline GO:0008289 & lipid binding & 3.1318124 & 0.0007382 & 0.0671783 \\
\hline \multicolumn{5}{|c|}{ Up-regulated GOTERM - CC } \\
\hline GO:0044421 & extracellular region part & 19.37912347 & $4.17712 \mathrm{E}-20$ & $1.38801 \mathrm{E}-17$ \\
\hline GO:0005615 & extracellular space & 19.292176 & $5.103 \mathrm{E}-20$ & $1.388 \mathrm{E}-17$ \\
\hline GO:0005576 & extracellular region & 18.176451 & $6.661 \mathrm{E}-19$ & $1.208 \mathrm{E}-16$ \\
\hline GO:0071944 & cell periphery & 5.2176385 & $6.058 \mathrm{E}-06$ & 0.0008239 \\
\hline GO:0005886 & plasma membrane & 5.0135407 & $9.693 \mathrm{E}-06$ & 0.0010546 \\
\hline GO:0045111 & intermediate filament cytoskeleton & 4.667064834 & $2.15246 \mathrm{E}-05$ & 0.001951564 \\
\hline GO:0005882 & intermediate filament & 4.359055191 & $4.37467 \mathrm{E}-05$ & 0.00339974 \\
\hline GO:0005887 & integral to plasma membrane & 2.9865361 & 0.0010315 & 0.0633503 \\
\hline GO:0031226 & intrinsic to plasma membrane & 2.979607735 & 0.001048075 & 0.063350297 \\
\hline GO:0031012 & extracellular matrix & 2.7337115 & 0.0018462 & 0.1004355 \\
\hline \multicolumn{5}{|c|}{ Down-regulated GOTERM - BP } \\
\hline GO:0065007 & biological regulation & 4.6424608 & $2.278 \mathrm{E}-05$ & 0.0894996 \\
\hline GO:0007010 & cytoskeleton organization & 4.071853181 & $8.47514 \mathrm{E}-05$ & 0.166494102 \\
\hline GO:0050789 & regulation of biological process & 3.4323117 & 0.0003696 & 0.3087138 \\
\hline GO:0050794 & regulation of cellular process & 3.367305 & 0.0004292 & 0.3087138 \\
\hline GO:0009987 & cellular process & 3.3527703 & 0.0004438 & 0.3087138 \\
\hline GO:0030029 & actin filament-based process & 3.326574762 & 0.000471439 & 0.308713781 \\
\hline GO:0030036 & actin cytoskeleton organization & 3.226733997 & 0.000593289 & 0.333004416 \\
\hline GO:0051781 & positive regulation of cell division & 2.989019573 & 0.001025606 & 0.503700601 \\
\hline GO:0043242 & negative regulation of protein complex disassembly & 2.810919174 & 0.001545542 & 0.623262207 \\
\hline GO:0006355 & regulation of transcription, DNA-dependent & 2.705378964 & 0.001970702 & 0.623262207 \\
\hline
\end{tabular}


Table 2. Continued

\begin{tabular}{|c|c|c|c|c|}
\hline GO.ID & Term/gene function & Enrichment.Score & p-value & FDR \\
\hline \multicolumn{5}{|c|}{ Down-regulated GOTERM - MF } \\
\hline GO:0004012 & phospholipid-translocating ATPase activity & 3.1925291 & 0.0006419 & 0.3770954 \\
\hline GO:0005515 & protein binding & 2.7511265 & 0.0017737 & 0.3770954 \\
\hline GO:0008270 & zinc ion binding & 2.5598316 & 0.0027553 & 0.3770954 \\
\hline GO:0043395 & heparan sulfate proteoglycan binding & 2.5544356 & 0.0027897 & 0.3770954 \\
\hline GO:0008144 & drug binding & 2.487412564 & 0.003255273 & 0.377095398 \\
\hline GO:0022804 & active transmembrane transporter activity & 2.439956658 & 0.003631143 & 0.377095398 \\
\hline GO:0008081 & phosphoric diester hydrolase activity & 2.380042173 & 0.004168289 & 0.377095398 \\
\hline GO:0016820 & $\begin{array}{l}\text { hydrolase activity, acting on acid anhydrides, catalyzing } \\
\text { transmembrane movement of substances }\end{array}$ & 2.352522558 & 0.004440966 & 0.377095398 \\
\hline GO:0033613 & activating transcription factor binding & 2.339046107 & 0.004580933 & 0.377095398 \\
\hline GO:0043167 & ion binding & 2.3265353 & 0.0047148 & 0.3770954 \\
\hline \multicolumn{5}{|c|}{ Down-regulated GOTERM - CC } \\
\hline GO:0030863 & cortical cytoskeleton & 4.349848737 & $4.46839 \mathrm{E}-05$ & 0.024308052 \\
\hline GO:0005815 & microtubule organizing center & 3.797329796 & 0.000159467 & 0.043374962 \\
\hline GO:0044448 & cell cortex part & 3.4857585 & 0.0003268 & 0.0554062 \\
\hline GO:0044464 & cell part & 3.300119 & 0.000501 & 0.0554062 \\
\hline GO:0005623 & cell & 3.2930704 & 0.0005092 & 0.0554062 \\
\hline GO:0005813 & centrosome & 3.070402158 & 0.00085035 & 0.077098422 \\
\hline GO:0030864 & cortical actin cytoskeleton & 2.9565723 & 0.0011052 & 0.0858872 \\
\hline GO:0005856 & cytoskeleton & 2.8446769 & 0.00143 & 0.0972371 \\
\hline GO:0044459 & plasma membrane part & 2.7103367 & 0.0019483 & 0.1177659 \\
\hline GO:0009986 & cell surface & 2.366643054 & 0.004298896 & 0.233859947 \\
\hline
\end{tabular}

BP: biological processes; MF: molecular function; CC: GO cell component.
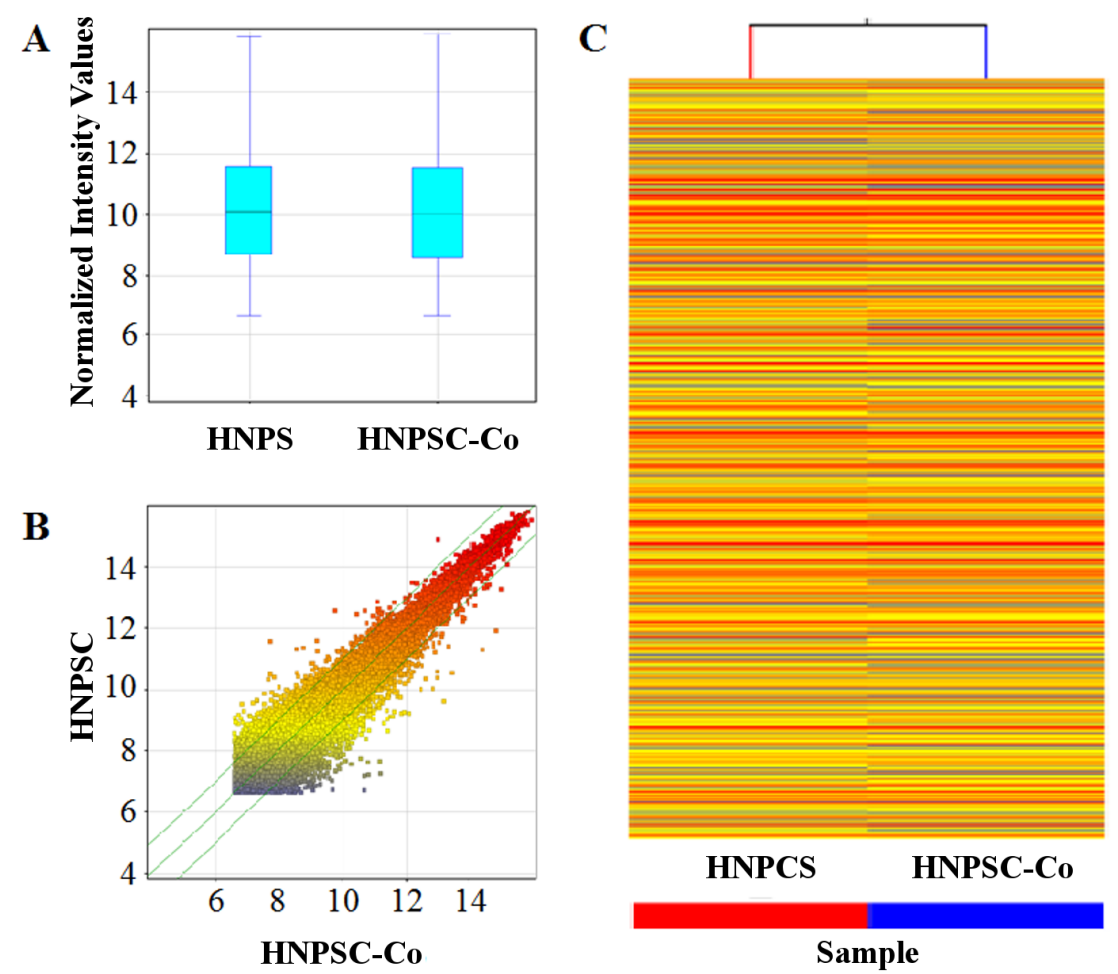

Figure 1. The overview of DEGs. A) Boxplot view is used to look at and compare the distributions of expression values for the samples in an experiment after normalization. B) Scatterplot is a visualization that is useful for assessing the variation (or reproducibility) between chips. C) Heat map and hierarchical clustering. Hierarchical Clustering for expression level of all genes collected. "Red" indicates high relative expression, and "blue" indicates low relative expression. 
tubule organizing center (Table 2). In addition, the top ten counts of the significant enrichment terms and the $p$-value trees were also showed in the Suppl. Figures 1a and $1 \mathrm{~b}$.
KEGG pathway analysis. The most significantly enriched pathways of the up-regulated DEGs and down-regulated DEGs by performing KEGG analysis were showed in Table 3,

Table 3. KEGG pathway analysis of DEGs in primary PSCs after cross-talked with BXPC-3 Up-regulated DEGs

\begin{tabular}{|c|c|c|c|c|c|}
\hline Pathway ID & Definition & Fisher-p-value & FDR & Enrichment & Genes \\
\hline \multicolumn{6}{|c|}{ Up-regulated DEGs } \\
\hline hsa05323 & Rheumatoid arthritis & $9.33768 \mathrm{E}-08$ & $1.23257 \mathrm{E}-05$ & 7.029761 & $\begin{array}{l}\text { CCL2//CCL3//CSF2//CXCL1//CXCL5//CXCL6// } \\
\text { HLA-DQA1//HLA-DRB5//ICAM1//IL11//IL15// } \\
\text { IL1B//IL6//IL8//LTB//MMP3 }\end{array}$ \\
\hline hsa04060 & $\begin{array}{l}\text { Cytokine-cytokine receptor } \\
\text { interaction }\end{array}$ & $1.5876 \mathrm{E}-06$ & 0.000104781 & 5.79926 & $\begin{array}{l}\text { CCL2//CCL21//CCL3//CSF2//CSF2RA//CSF2RB// } \\
\text { CSF3R//CXCL1//CXCL2//CXCL3//CXCL5// } \\
\text { CXCL6//IFNA1//IFNA6//IL11//IL15//IL1B//IL1R2// } \\
\text { IL2RB//IL6//IL8//LIF//LTA//LTB//TNFRSF8// } \\
\text { TNFSF15 }\end{array}$ \\
\hline hsa05150 & $\begin{array}{l}\text { Staphylococcus aureus infec- } \\
\text { tion }\end{array}$ & $2.93439 \mathrm{E}-06$ & 0.000129113 & 5.532482 & $\begin{array}{l}\text { C1QB//C3//FCGR2A//FCGR2C//FCGR3A//FC- } \\
\text { GR3B//FPR1//HLA-DQA1//HLA-DRB5//ICAM1// } \\
\text { PTAFR }\end{array}$ \\
\hline hsa04380 & Osteoclast differentiation & $8.96416 \mathrm{E}-06$ & 0.000295817 & 5.04749 & $\begin{array}{l}\text { FCGR2A//FCGR2C//FCGR3A//FCGR3B//IL1B// } \\
\text { LILRA1//LILRB1//LILRB2//LILRB3//LILRB5// } \\
\text { NCF1//OSCAR//RELB//SOCS1//SPI1//TYROBP }\end{array}$ \\
\hline hsa05140 & Leishmaniasis & 4.14197E-05 & 0.00109348 & 4.382793 & $\begin{array}{l}\text { C3//FCGR2A//FCGR2C//FCGR3A//FCGR3B// } \\
\text { HLA-DQA1//HLA-DRB5//IL1B//NCF1//PTGS2// } \\
\text { PTPN6 }\end{array}$ \\
\hline hsa05152 & Tuberculosis & $5.46894 \mathrm{E}-05$ & 0.001203167 & 4.262097 & $\begin{array}{l}\text { BCL2//C3//CALML5//CAMP//CTSS//FCGR2A// } \\
\text { FCGR2C//FCGR3A//FCGR3B//HLA-DQA1//HLA- } \\
\text { DRB5//IFNA1//IFNA6//IL1B//IL6//IRAK2//LSP1// } \\
\text { MALT1 }\end{array}$ \\
\hline hsa04978 & Mineral absorption & 0.000356498 & 0.006722528 & 3.447943 & $\begin{array}{l}\text { FXYD2//MT1F//MT1G//MT1H//MT1X//SL- } \\
\text { C11A1//SLC26A3//STEAP1 }\end{array}$ \\
\hline hsa05164 & Influenza A & 0.0004297 & 0.007090056 & 3.366834 & $\begin{array}{l}\text { CCL2//DDX58//HLA-DQA1//HLA-DRB5// } \\
\text { ICAM1//IFNA1//IFNA6//IL1B//IL6//IL8//MX1// } \\
\text { OAS1//OAS2//OAS3//PRSS1//RSAD2 }\end{array}$ \\
\hline hsa04640 & Hematopoietic cell lineage & 0.000966451 & 0.01379606 & 3.01482 & $\begin{array}{l}\text { CSF2//CSF2RA//CSF3R//GP1BA//HLA-DRB5// } \\
\text { IL11//IL1B//IL1R2//IL6//THPO }\end{array}$ \\
\hline hsa04630 & Jak-STAT signaling pathway & 0.001045156 & 0.01379606 & 2.980819 & $\begin{array}{l}\text { CSF2//CSF2RA//CSF2RB//CSF3R//IFNA1//IFNA6// } \\
\text { IL11//IL13RA2//IL15//IL2RB//IL6//LIF//PTPN6// } \\
\text { SOCS1 }\end{array}$ \\
\hline hsa05146 & Amoebiasis & 0.001169034 & 0.01402841 & 2.932173 & $\begin{array}{l}\text { CSF2//CXCL1//IL1B//IL1R2//IL6//IL8//LAMA5// } \\
\text { LAMC2//MUC2//PLCB2//SERPINB2 }\end{array}$ \\
\hline hsa05144 & Malaria & 0.001878932 & 0.02066825 & 2.726089 & CCL2//DARC//GYPB//ICAM1//IL1B//IL6//IL8 \\
\hline hsa05162 & Measles & 0.002541945 & 0.02581052 & 2.594834 & $\begin{array}{l}\text { DDX58//IFNA1//IFNA6//IL1B//IL2RB//IL6//MX1// } \\
\text { OAS1//OAS2//OAS3//RAB9B//TNFAIP3 }\end{array}$ \\
\hline hsa05133 & Pertussis & 0.004221993 & 0.03842717 & 2.374483 & $\begin{array}{l}\text { C1QB//C3//CALML5//CXCL5//CXCL6//IL1B// } \\
\text { IL6//IL8 }\end{array}$ \\
\hline hsa04621 & $\begin{array}{l}\text { NOD-like receptor signaling } \\
\text { pathway }\end{array}$ & 0.004366724 & 0.03842717 & 2.359844 & CCL2//CXCL1//CXCL2//IL1B//IL6//IL8//TNFAIP3 \\
\hline hsa04062 & Chemokine signaling pathway & 0.006538561 & 0.05394313 & 2.184518 & $\begin{array}{l}\text { CCL2//CCL21//CCL3//CXCL1//CXCL2//CXCL3// } \\
\text { CXCL5//CXCL6//GRK4//IL8//NCF1//PLCB2// } \\
\text { PREX1//VAV1 }\end{array}$ \\
\hline hsa05160 & Hepatitis C & 0.007325769 & 0.05688244 & 2.135147 & $\begin{array}{l}\text { CLDN1//CLDN20//CLDN7//DDX58//IFIT1// } \\
\text { IFNA1//IFNA6//IL8//OAS1//OAS2//OAS3 }\end{array}$ \\
\hline hsa04145 & Phagosome & 0.008203582 & 0.0601596 & 2.085996 & $\begin{array}{l}\text { C3//COLEC11//CTSS//FCGR2A//FCGR2C// } \\
\text { FCGR3A//FCGR3B//HLA-DQA1//HLA-DRB5// } \\
\text { NCF1//TUBA8//TUBB8 }\end{array}$ \\
\hline hsa05322 & Systemic lupus erythematosus & 0.009073344 & 0.06303587 & 2.042233 & $\begin{array}{l}\text { C1QB//C3//FCGR2A//FCGR2C//FCGR3A//FC- } \\
\text { GR3B//HIST1H2AI//HIST1H3F//HIST2H2AB// } \\
\text { HLA-DQA1//HLA-DRB5 }\end{array}$ \\
\hline hsa05132 & Salmonella infection & 0.0111002 & 0.0732613 & 1.954669 & $\begin{array}{l}\text { CCL3//CSF2//CXCL1//CXCL2//CXCL3//IL1B// } \\
\text { IL6//IL8 }\end{array}$ \\
\hline hsa04666 & $\begin{array}{l}\text { Fc gamma R-mediated phago- } \\
\text { cytosis }\end{array}$ & 0.01820236 & 0.1144148 & 1.739872 & $\begin{array}{l}\text { FCGR2A//FCGR2C//FCGR3A//MYO10//NCF1// } \\
\text { PTPRC//SCIN//VAV1 }\end{array}$ \\
\hline
\end{tabular}


Table 3. Continued

\begin{tabular}{|c|c|c|c|c|c|}
\hline Pathway ID & Definition & Fisher-p-value & FDR & Enrichment & Genes \\
\hline hsa04940 & Type I diabetes mellitus & 0.02005665 & 0.1203399 & 1.697742 & HLA-DQA1//HLA-DRB5//IL1B//LTA//PTPRN2 \\
\hline hsa05166 & HTLV-I infection & 0.02545731 & 0.1461028 & 1.594187 & $\begin{array}{l}\text { ATM//ATR//CSF2//EGR1//EGR2//FZD5//HLA- } \\
\text { DQA1//HLA-DRB5//ICAM1//IL15//IL1R2// } \\
\text { IL2RB//IL6//LTA//RELB//SPI1 }\end{array}$ \\
\hline hsa04672 & $\begin{array}{l}\text { Intestinal immune network } \\
\text { for IgA production }\end{array}$ & 0.02797797 & 0.1538788 & 1.553184 & HLA-DQA1//HLA-DRB5//IL15//IL6//PIGR \\
\hline hsa05142 & $\begin{array}{l}\text { Chagas disease (American } \\
\text { trypanosomiasis) }\end{array}$ & 0.02955051 & 0.1560267 & 1.529435 & C1QB//C3//CCL2//CCL3//IL1B//IL6//IL8//PLCB2 \\
\hline hsa05020 & Prion diseases & 0.03328155 & 0.1589259 & 1.477796 & C1QB//EGR1//IL1B//IL6 \\
\hline hsa05143 & African trypanosomiasis & 0.03328155 & 0.1589259 & 1.477796 & ICAM1//IL1B//IL6//PLCB2 \\
\hline hsa04610 & $\begin{array}{l}\text { Complement and coagulation } \\
\text { cascades }\end{array}$ & 0.03371155 & 0.1589259 & 1.472221 & BDKRB1//C1QB//C3//F12//F7//THBD \\
\hline \multicolumn{6}{|c|}{ Down-regulated DEGs } \\
\hline hsa02010 & $\mathrm{ABC}$ transporters & 0.009810887 & 0.7359723 & 2.008292 & ABCA5//ABCB1//ABCB10//ABCC9//ABCG2 \\
\hline hsa00531 & $\begin{array}{l}\text { Glycosaminoglycan degrada- } \\
\text { tion }\end{array}$ & 0.01822253 & 0.7359723 & 1.739391 & HPSE2//HYAL1//HYAL3 \\
\hline hsa05166 & HTLV-I infection & 0.02981243 & 0.7359723 & 1.525603 & $\begin{array}{l}\text { ANAPC10//ANAPC4//APC//ATF2//CD40//HLA- } \\
\text { DMA//JAK3//MAP3K14//MYBL1//NFATC1// } \\
\text { NFYB//PDGFB//TP53INP1//WNT2B }\end{array}$ \\
\hline hsa04350 & TGF-beta signaling pathway & 0.04222372 & 0.7359723 & 1.374444 & BMP8A//COMP//ID4//NOG//SMAD5//ZFYVE16 \\
\hline hsa00071 & Fatty acid metabolism & 0.04230956 & 0.7359723 & 1.373561 & ACSL3//ADH1A//ADH1B//ADH1C \\
\hline
\end{tabular}

p-value is calculated by Fisher's exact test (Cut-off is p-value $<=0.05$, bioconductor package topGO). FDR: The False Discovery Rate of the listed GO term

Table 4. The annotation for top 3 modules.

\begin{tabular}{|c|c|c|c|}
\hline Term & FDR & p-value & Genes \\
\hline \multicolumn{4}{|l|}{ Module1 } \\
\hline response to lipopolysaccharide & 0.00000144 & $1.12 \mathrm{E}-09$ & CXCL1, PPBP, CXCL5, CXCL3, CNR1, CXCL2, BDKRB1, CXCL6 \\
\hline $\begin{array}{l}\text { G-protein coupled receptor signaling } \\
\text { pathway }\end{array}$ & $2.89 \mathrm{E}-13$ & $2.16 \mathrm{E}-16$ & $\begin{array}{l}\text { CXCL1, PTGER3, CXCL5, C3, CXCL3, TAS2R3, CXCL2, FPR1, CXCR1, CXCL6, PPBP, } \\
\text { CCL21, CHRM2, S1PR4, ADRA2A, HCAR3, SST }\end{array}$ \\
\hline CXCR chemokine receptor binding & $2.81 \mathrm{E}-10$ & $2.9 \mathrm{E}-13$ & CXCL1, PPBP, CXCL5, CXCL3, CXCL2, CXCL6 \\
\hline \multicolumn{4}{|l|}{ Module2 } \\
\hline positive regulation of cell proliferation & 0.009869553 & $6.65 \mathrm{E}-06$ & LIF, CSF2, EDNRB, BCL2, IGF1, IL15, HTR2B, IL11 \\
\hline immune response & $2.92 \mathrm{E}-08$ & $1.96 \mathrm{E}-11$ & LIF, CSF2, SLC11A1, CCL3, CCL2, LTB4R, IL15, CD40, FCGR3A, FCGR3B, CCL18, PTAFR \\
\hline inflammatory response & 0.000141686 & $9.54 \mathrm{E}-08$ & SLC11A1, CCL3, CCL2, LTB4R, TBXA2R, IL15, CD40, CCL18, PTAFR \\
\hline \multicolumn{4}{|l|}{ Module3 } \\
\hline intermediate filament & $3.83 \mathrm{E}-16$ & $1.70 \mathrm{E}-18$ & $\begin{array}{l}\text { KRTAP21-2, KRTAP6-2, KRTAP19-7, KRTAP20-1, KRTAP20-2, KRTAP21-1, KRTAP6-3, } \\
\text { KRTAP19-1, KRTAP13-2 }\end{array}$ \\
\hline
\end{tabular}

p-value is calculated by Fisher's exact test (Cut-off is p-value $<=0.05$ ). FDR: The False Discovery Rate

in which 28 signal transduction pathways were upregulated, and 5 were downregulated. The up-regulated DEGs were enriched in rheumatoid arthritis, staphylococcus aureus infection and cytokine-cytokine receptor interaction, and the down-regulated were enriched in $\mathrm{ABC}$ transporters, glycosaminoglycan degradation, HTLV-I infection, TGF-beta signaling pathway and fatty acid metabolism signaling pathway (Figure 2).

Key nodes and modules analysis of PPI network. After processing through the STRING database, 890 nodes and 3922 edges were selected out, which constituted the PPI network (data not shown). We selected out 10 key genes based on the data of the PPI network, including IL6 (interleukin 6),IL8 (C-X-C motif chemokine ligand 8), IL1B (interleukin 1 beta), BCL2 (apoptosis regulator), CCL2 (C-C motif chemokine ligand 2), CSF2 (colony stimulating factor 2), KIT (proto-oncogene receptor tyrosine kinase), ICAM1 (intercellular adhesion molecule 1), PTPRC (protein tyrosine phosphatase, receptor type C) and IGF1 (insulin like growth factor 1). The highest degree gene was IL6, whose degree was 124. In addition, Top 3 significant modules were analyzed and corresponding functional and pathway enrichment analysis were done subsequently (Figure 3 ). The significant pathways associated with genes in module 1-3 are displayed in Table 4. In survival analysis, high expression of IL6 was linked with worse OS for PDAC patients, as well as IL8, IL1B, BCL2 and CSF2 (Figure 4). 


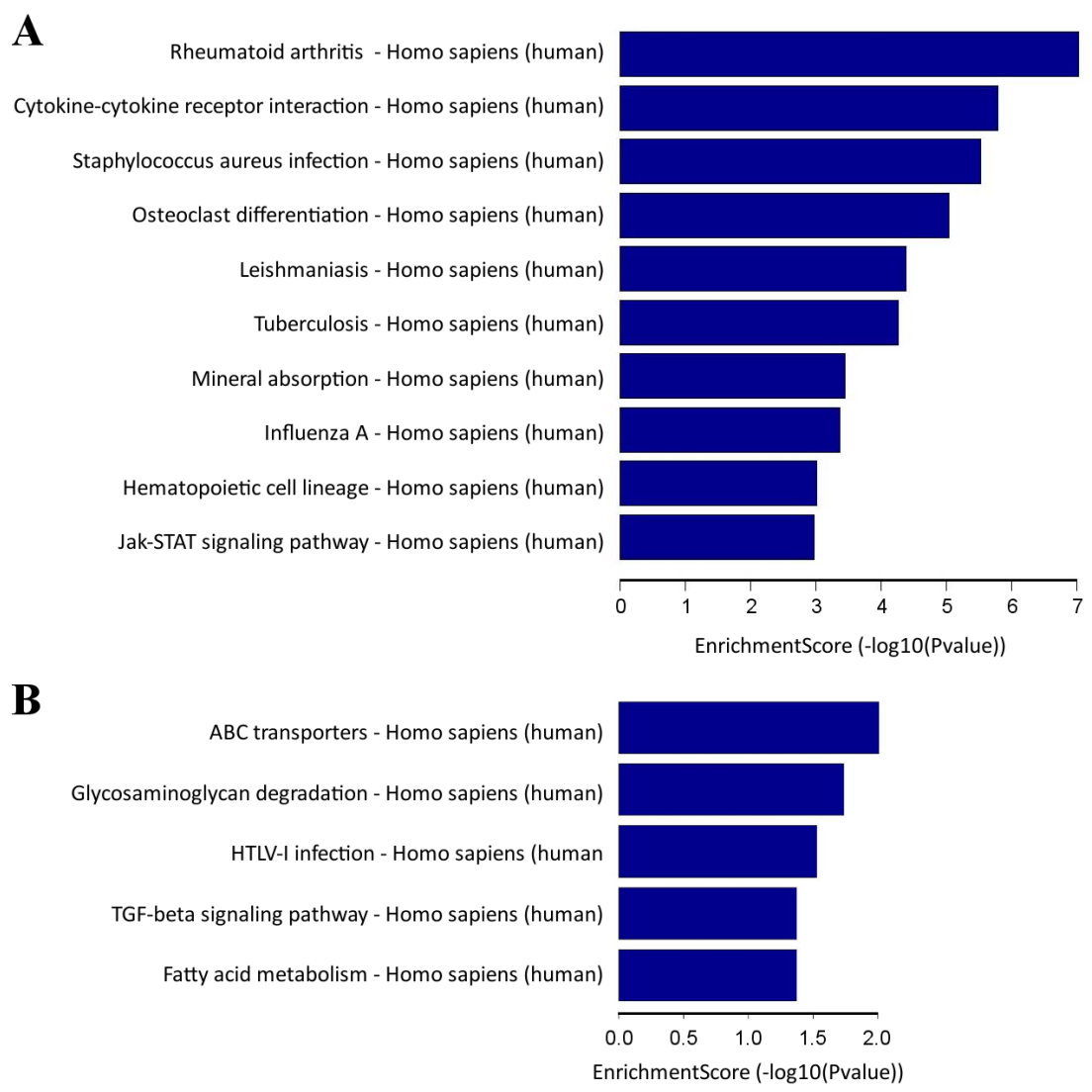

Figure 2. The results of KEGG analysis. A) Top 10 up-regulated hsa_EnrichmentScore; B) Top 10 down-regulated hsa_EnrichmentScore.
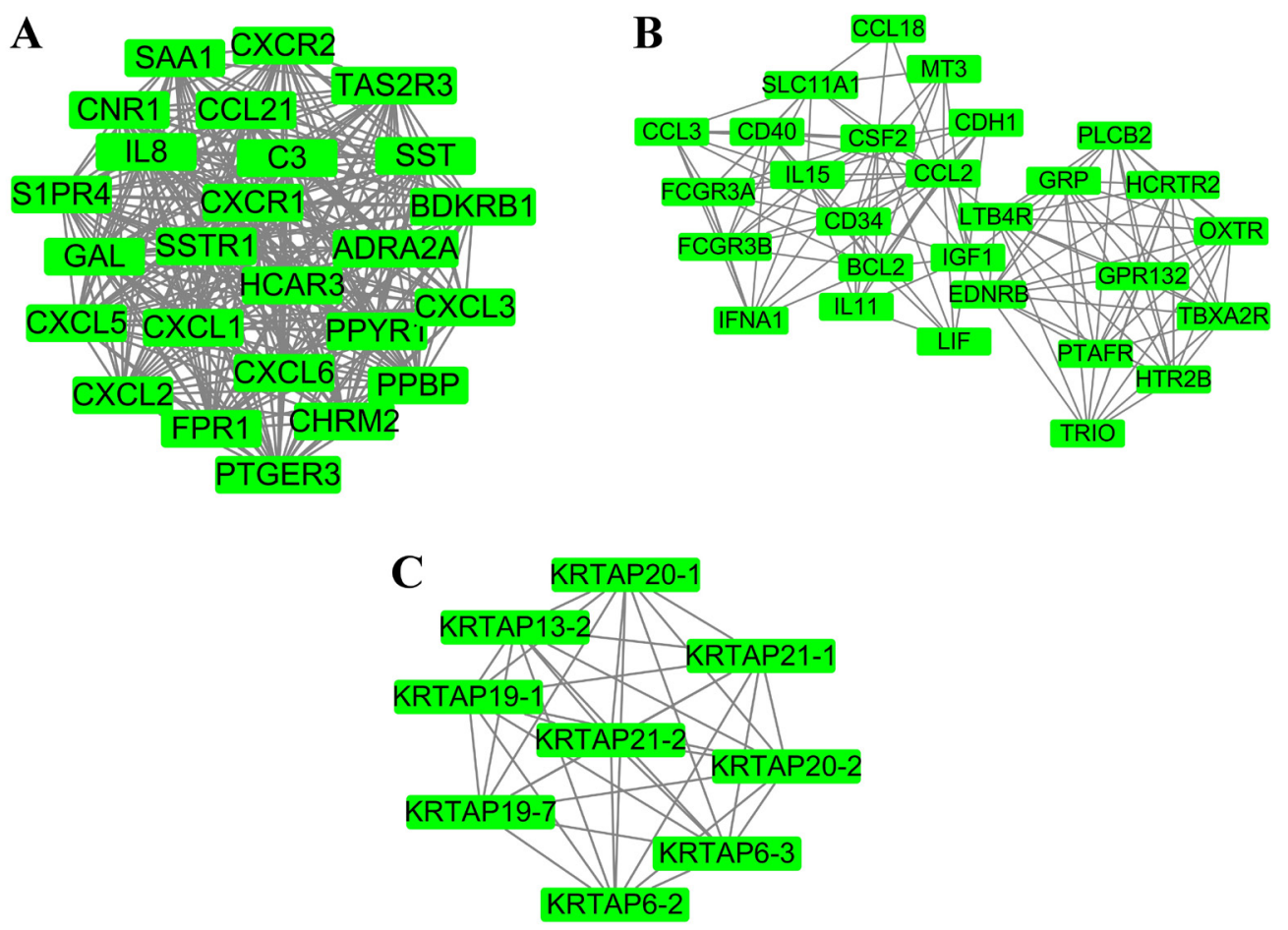

Figure 3. Top 3 modules from the PPI network. A) module 1, B) module 2, C) module 3 

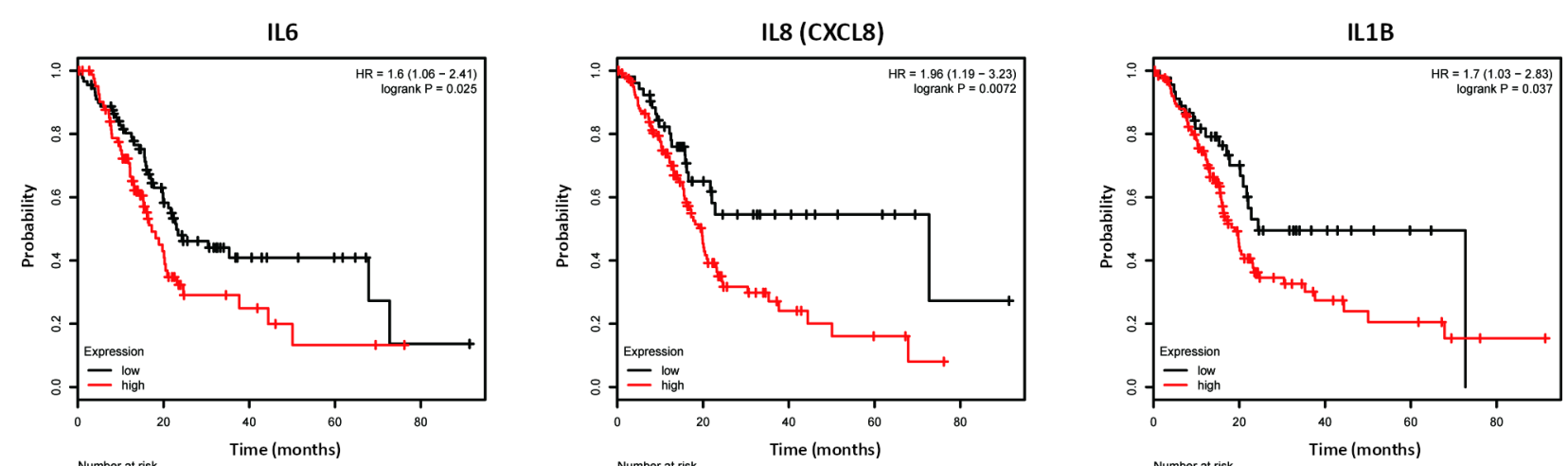

Number at risk
low 93
high 84
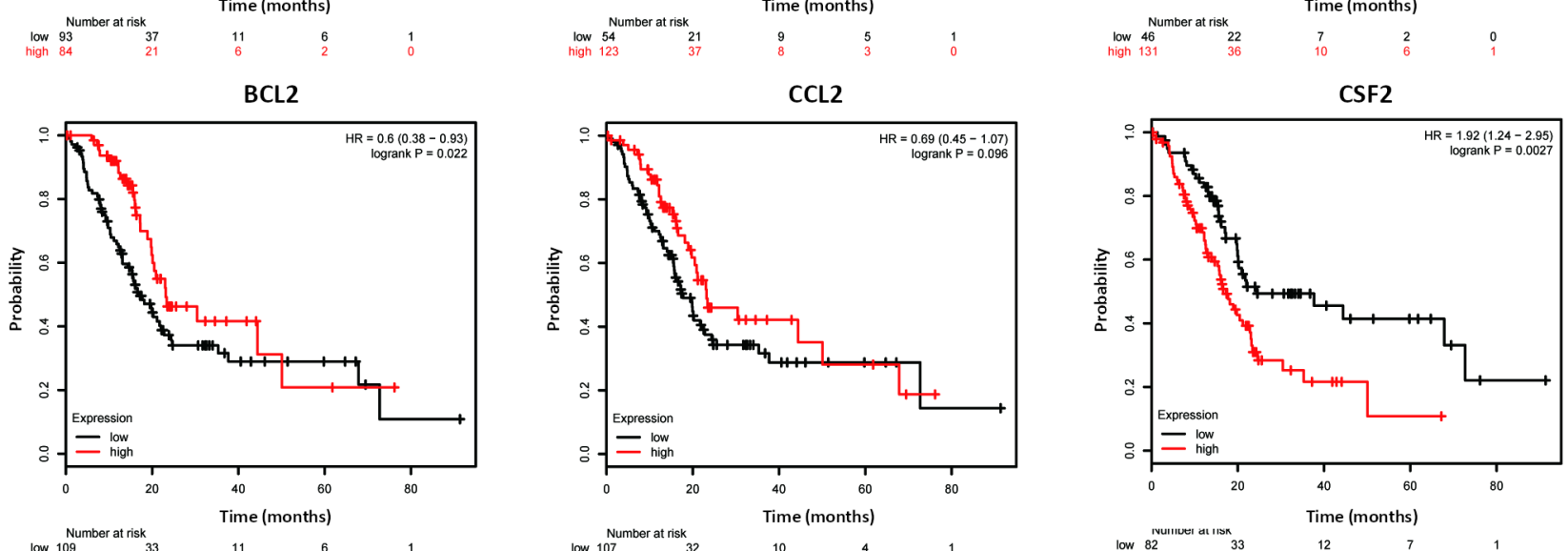

$\begin{array}{cc}\text { Number at risk } \\ \text { low } \\ \text { high } 69 & 33 \\ 68 & 25\end{array}$
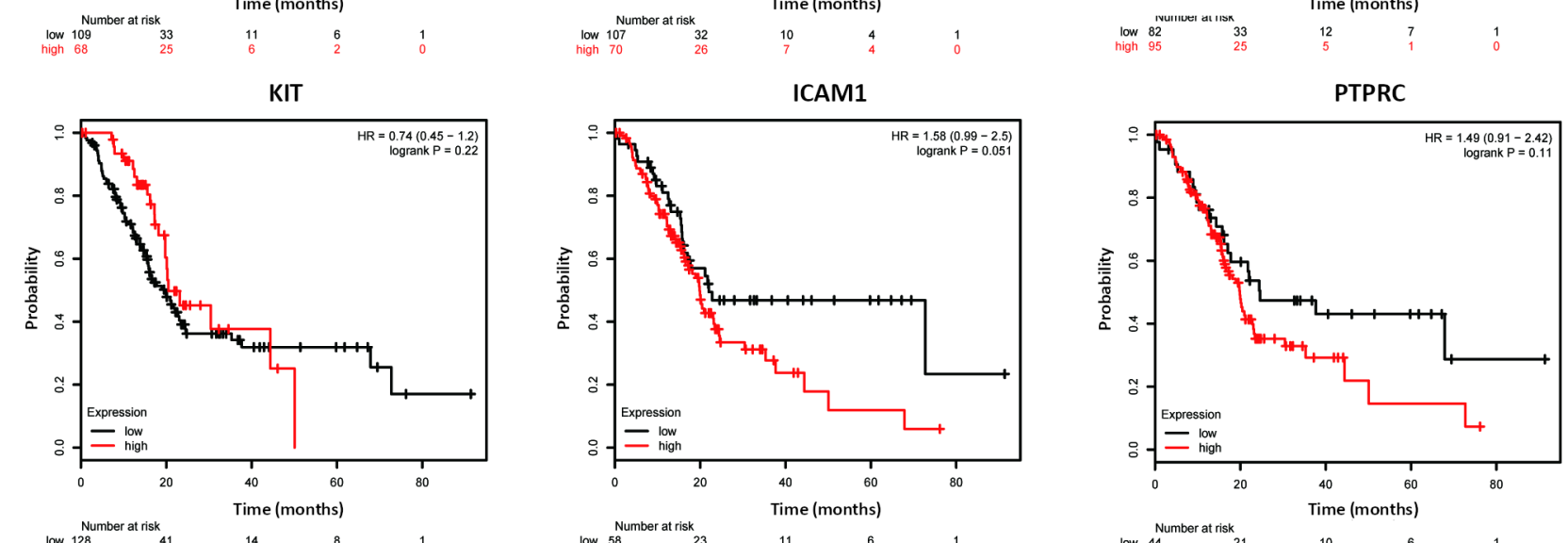

$\begin{array}{cc}\text { Number at risk } \\ \text { low } \\ \text { high } & 428\end{array}$

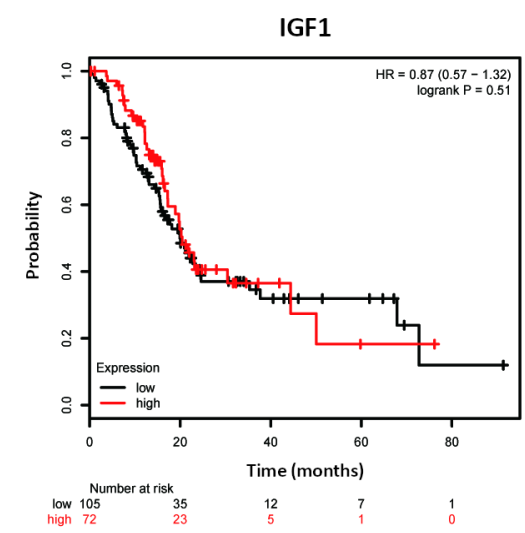

Figure 4. Prognostic value of hub genes: IL6, IL8, IL1B, BCL2, CCL2, CSF2, KIT, ICAM1, PTPRC, IGF1; HR, hazard ratio; CI, confidence interval; adj. p, adjusted p-value 


\section{Discussion}

Progression of PDAC is promoted by desmoplasia that is mostly induced by PSCs, and the interaction between PDAC cells and PSCs is receiving increasing attention [15]. Understanding the molecular mechanism of interaction between PDAC cells and PSCs is important for diagnosis and treatment of PDAC. Considering that high-throughput sequencing and microarray can display expression degrees of genes in the human genome synchronously, it has been widely applied to predict the potential targets of PDAC [24]. In the current research, we identified 958 up-regulated and 846 down-regulated DEGs in primary PSCs co-cultured with or without BXPC-3 via bioinformatics analysis. Function annotation suggested that DEGs were significantly enriched in defense response, immune responses, chemokine activity and cytoskeleton. Autophagy is a lysosomal-mediated cell death process, and autophagy in cancer cells is impeded to some extent. Compared to other epithelial tumors, pancreatic cancer cells have increased levels of autophagy and play an important role in cell defense response [11]. Mathematical models of pancreatic cancer have also been established to illustrate the feedback effects between tumor growth rate and endothelial cells and immune responses [25]. Meanwhile, researches confirmed that Galectin-1 induced chemokine production and proliferation of PSCs [26]. In addition, PSCs could activate cadherin-11 and thus mediate cytoskeletal remodeling [27]. The results of KEGG pathway analysis suggested that DEGs were significantly related with TGF-beta signaling pathway and $\mathrm{ABC}$ transporters, which are of potential significance for target treatment in PDAC patients [14]. Researches have shown that $\mathrm{ABC}$ transporters play a vital role in cancer susceptibility, initiation and progression in individuals with pancreatic cancer, as well as in the immune system response and sensitivity of tumor cells to chemotherapy [28].

By building the PPI network, we selected several key genes that can provide targets for the treatment researches in PDAC. IL6 is secreted by tumor cells and PSCs in the PDAC microenvironment, which is linked to various tumor cell biological behaviors such as proliferation, angiogenesis, EMT, and chemoresistance [14]. IL8, chemokine (C-X-C motif) ligand 8 (CXCL8), is an important pro-inflammatory chemokine secreted by PDAC cells, which mediates the angiogenesis and survival signaling pathways in PDAC [29]. Furthermore, the cancer cell-derived IL8 could activate PSC to promote gemcitabine resistance [30]. Galectin-3, a member of $\beta$-galactoside specific lectins family, could contribute to the resistance, as it was illustrated that Galectin-3 could activate PSCs, inducing IL8 production via integrin subunit beta 1 , which activates NF- $\kappa \mathrm{B}$ signaling through integrin-linked kinase [31]. In addition, the positive expression of CXCR1 in PDAC, a receptor for CXCL8/IL8, was proved to be linked with lymph node metastasis and a poor survival rate [32]. In conclusion, IL8 could be a therapeutic target for PDAC.
IL1B, a member of interleukin family, which is implicated in a variety of cellular functions, including cell differentiation, proliferation and apoptosis. In human pancreas, it was demonstrated that IL1B was mainly located in pancreatic alpha cells [33]. Previous research declared that there was an autocrine loop between TGF- $\beta$ and IL1B in activated pancreatic stellate cells [34]. Although there is evidence that IL1B was associated with cancers such as lung cancer and gastric cancer [35, 36], there is few research on pancreatic cancer. As previous article showed, IL1B in tumor microenvironment was linked with a more aggressive tumor phenotype $[37,38]$, this gene is worthy of being studied for PDAC treatment. BCL2, which was found activated in PDAC, mainly took part in the resistance of apoptosis and necrosis [39, 40]. Interestingly, Song et al. found that high expression of BCL2 was a favorable prognostic indicator for PDAC patients [41]. In addition, BCL2 was involved in the modulation of several pathways such as nuclear factor- $\kappa \mathrm{B}(\mathrm{NF}-\kappa \mathrm{B})$, mitogen-activated protein kinase (MAPK), signal transducer and activator of transcription 3 (STAT3) [39]. Besides, it was demonstrated that there was a significant relationship between BCL2 and IL8 [42]. CCL2 is a member of superfamily of secreted proteins associated with inflammatory and immunoregulatory processes, and has been clarified in diseases related to monocytic infiltrates. The poor survival of PDAC patients is partly owing to its unique tumor microenvironment, which is characterized by poor infiltration of effector $\mathrm{T}$ cells and more inflammatory cells such as monocytes and macrophages [43]. In the PDAC tumor microenvironment, CCL2 can be driven by both tumor cells and non-malignant cells and the serum levels of CCL2 were higher than in normal healthy tissue $[44,45]$. In addition, although CCL2 had no direct effect on tumor cells, the inhibition of CCL2 has shown its potential efficacy when combined with stereotactic ablative body radiotherapy [45]. As the loss of CCL2 could contribute to anti-CD40 therapy non-response for PDAC, CCL2 may be a novel biomarker to select suitable patients [46]. CSF2, also known as CSF or granulocyte-macrophage colony stimulating factor (GMCSF), plays a crucial role in the evasion of antitumor immunity in tumor microenvironment. It was documented that CSF could be produced by malignant cells and it may synergize with PSC-derived factors such as IL-6 to promote immune suppression process in PDAC [47-49]. KIT, also known as C-Kit or CD117, is the only hub gene that was down-regulated (primary PSCs after cross-talk with BXPC-3 vs. primary PSCs) in current study. KIT was documented to be related to the pancreatic neuroendocrine tumor progression and metastasis. Highly expressed KIT was remarkably associated with shorter patient survival time and it may be a prognostic marker for such tumors $[50,51]$. But it seems to have nothing to do with the undifferentiated pancreatic cancer [52]. What's more, targeting KIT pathway via inhibiting KIT tyrosine kinase receptor could be a promising therapy for patients bearing pancreatic neuroendocrine tumors with KIT mutations [53, 
54]. ICAM1 is typically expressed on endothelial cells and cells of the immune system, and C Huang et al. demonstrated that IL-35 could promote PDAC metastasis through mediating ICAM1 expression [55]. The next gene, PTPRC is known to participate in various biological processes including cell growth, differentiation, mitosis, and malignant transformation. And it was showed to be linked with multiple sclerosis [56] and T-cell acute lymphoblastic leukemia [57]. However, there is a few evidence that it was associated with pancreatic cancer. IGF1 is a member of a family of proteins implicated in mediating growth and development, and was proven to be linked to metastasis of pancreatic cancer cells [58]. Module analysis of the PPI network uncovered that the interaction between PSC and PDAC cell was mainly associated with CXCR chemokine receptor binding, immune response, G-protein coupled receptor signaling pathway, intermediate filament etc. Abnormal hypermethylation is a typical symptom of pancreatic cancer, and studies have shown that the expression of CXCR4 in human pancreatic cancer is influenced by DNA methylation [59]. The typical expression of G-protein coupled receptor signaling pathway in human pancreatic cancer is Neurotensin Responsiveness and Mitogenic Stimulation [60]. The immune response in human pancreatic cancer such as intratumoral and peritumoral T-cell infiltration was a favorable prognostic sign [61]. In pancreatic cancer cells, an abnormal number of keratin fibers can be found, making these cells an ideal model for studying the role of intermediate filaments for cell mechanical properties [62].

In conclusion, the results provided a global analysis of DEGs, which could be implicated in the interaction between BXPC-3 and PSCs and reflect the key roles of PSCs in tumor microenvironment and cancer progression. The study shows a series of meaningful targets for future research on molecular mechanisms and biomarkers. However, further molecular biological researches are needed to explain the function of the identified DEGs in PDAC cells.

Supplementary information is available in the online version of the paper.

Acknowledgments: This work was supported by grants from the Postdoctoral Science Foundation of China (2013M530243), Science and Technology Development Funding of Yangzhou City\{the Social Development of Science and Technology Research Projects of Yangzhou City \}( 2012123), the Jiangsu Province Natural Science Foundation of China (BK20140495), and the Six Big Talent Peak Projects of Jiangsu Province (2014-WSW-078), National Natural Science Funding of China (81572344), Postdoctoral Science Foundation of Jiangsu Province (2013), "Promote health development by science and technology" program of Jiangsu Province: focus on the subject of medical science (KF201225), Academic science and technology innovation fund for College Students (x20160750, x20160753, x20160774, x20160783, x20180714), training project of key talents of youth medicine in Jiangsu province, China (QNRC2016330).

\section{References}

[1] JEMAL A, SIEGEL R, XU J, WARD E. Cancer statistics, 2010. CA Cancer J Clin 2010; 60: 277-300. https://doi.org/10.3322/ caac. 20073

[2] TANG D, WANG D, YUAN Z, XUE X, ZHANG Y et al. Persistent activation of pancreatic stellate cells creates a microenvironment favorable for the malignant behavior of pancreatic ductal adenocarcinoma. Int J Cancer 2013; 132: 993-1003. https://doi.org/10.1002/ijc.27715

[3] KWON JJ, NABINGER SC, VEGA Z, SAHU SS, ALLURI RK et al. Pathophysiological role of microRNA-29 in pancreatic cancer stroma. Sci Rep 2015; 5: 11450. https://doi. org/10.1038/srep 11450

[4] BACHEM MG, SCHNEIDER E, GROSS H, WEIDENBACH $\mathrm{H}$, SCHMID RM et al. Identification, culture, and characterization of pancreatic stellate cells in rats and humans. Gastroenterology 1998; 115: 421-432.

[5] APTE MV, PARK S, PHILLIPS PA, SANTUCCI N, GOLDSTEIN D et al. Desmoplastic reaction in pancreatic cancer: role of pancreatic stellate cells. Pancreas 2004; 29: 179-187.

[6] MASAMUNE A, KIKUTA K, WATANABE T, SATOH K, HIROTA $M$ et al. Hypoxia stimulates pancreatic stellate cells to induce fibrosis and angiogenesis in pancreatic cancer. Am J Physiol Gastrointest Liver Physiol 2008; 295: G709-717. https://doi.org/10.1152/ajpgi.90356.2008

[7] XU Z, VONLAUFEN A, PHILLIPS PA, FIALA-BEER E, ZHANG X et al. Role of pancreatic stellate cells in pancreatic cancer metastasis. Am J Pathol 2010; 177: 2585-2596. https://doi.org/10.2353/ajpath.2010.090899

[8] JIANG X, ABIATARI I, KONG B, ERKAN M, DE OLIVEIRA $\mathrm{T}$ et al. Pancreatic islet and stellate cells are the main sources of endocrine gland-derived vascular endothelial growth factor/prokineticin-1 in pancreatic cancer. Pancreatology 2009; 9: 165-172. https://doi.org/10.1159/000178888

[9] LI X, MA Q, XU Q, DUAN W, LEI J et al. Targeting the Cancer-Stroma Interaction: A Potential Approach for Pancreatic Cancer Treatment. Curr Pharm Des 2012; 18: 2404-2415

[10] APTE MV, WILSON JS. Dangerous liaisons: Pancreatic stellate cells and pancreatic cancer cells. J Gastroenterol Hepatol 2012; 27 Suppl 2: 69-74. https://doi.org/10.1111/j.14401746.2011.07000.x

[11] KANG R, TANG D. Autophagy in pancreatic cancer pathogenesis and treatment. Am J Cancer Res 2012; 2: 383-396.

[12] ERKAN M, REISER-ERKAN C, MICHALSKI CW, KLEEFF J. Tumor microenvironment and progression of pancreatic cancer. Exp Oncol 2010; 32: 128-131.

[13] VAN LAETHEM JL, VERSLYPE C, IOVANNA JL, MICHL $\mathrm{P}, \mathrm{CONROY} \mathrm{T}$ et al. New strategies and designs in pancreatic cancer research: consensus guidelines report from a European expert panel. Ann Oncol 2012; 23: 570-576. https://doi. org/10.1093/annonc/mdr351

[14] WU Q, TIAN Y, ZHANG J, ZHANG H, GU F et al. Functions of pancreatic stellate cell-derived soluble factors in the microenvironment of pancreatic ductal carcinoma. Oncotarget 2017; 8: 102721-102738. https://doi.org/10.18632/oncotarget. 21970 
[15] TANG D, WANG D, YUAN Z, XUE X, ZHANG Y et al. Persistent activation of pancreatic stellate cells creates a microenvironment favorable for the malignant behavior of pancreatic ductal adenocarcinoma. Int J Cancer 2013: 132: 993-1003. https://doi.org/10.1002/ijc.27715

[16] TANG D, GAO J, WANG S, YUAN Z, YE N et al. Apoptosis and anergy of $T$ cell induced by pancreatic stellate cells-derived galectin-1 in pancreatic cancer. Tumour Biol 2015; 36: 5617-5626. https://doi.org/10.1007/s13277-015-3233-5

[17] TANG D, ZHANG J, YUAN Z, GAO J, WANG S et al. Pancreatic satellite cells derived galectin-1 increase the progression and less survival of pancreatic ductal adenocarcinoma. PLoS One 2014; 9: e90476. https://doi.org/10.1371/journal. pone.0090476

[18] GENE ONTOLOGY CONSORTIUM. The Gene Ontology (GO) project in 2006. Nucleic Acids Res 2006; 34: D322-326. https://doi.org/10.1093/nar/gkj021

[19] ASHBURNER M, BALL CA, BLAKE JA, BOTSTEIN D, BUTLER $\mathrm{H}$ et al. Gene ontology: tool for the unification of biology. The Gene Ontology Consortium. Nat Genet 2000; 25: 25-29. https://doi.org/10.1038/75556

[20] KANEHISA M, GOTO S. KEGG: kyoto encyclopedia of genes and genomes. Nucleic Acids Res 2000; 28: 27-30.

[21] DENNIS G JR, SHERMAN BT, HOSACK DA, YANG J, GAO W et al. DAVID: Database for Annotation, Visualization, and Integrated Discovery. Genome Biol 2003; 4: P3.

[22] SEEBACHER J, GAVIN AC. SnapShot: Protein-Protein Interaction Networks. Cell 2011; 144: 1000-1000.e1. https:// doi.org/10.1016/j.cell.2011.02.025

[23] SHANNON P, MARKIEL A, OZIER O, BALIGA NS, WANG JT et al. Cytoscape: a software environment for integrated models of biomolecular interaction networks. Genome Res 2003; 13: 2498-2504. https://doi.org/10.1101/gr.1239303

[24] BRANDT R, GRUTZMANN R, BAUER A, JESNOWSKI R, RINGEL J et al. DNA microarray analysis of pancreatic malignancies. Pancreatology 2004; 4: 587-597. https://doi. org/10.1159/000082241

[25] LOUZOUN Y, XUE C, LESINSKI GB, FRIEDMAN A. A mathematical model for pancreatic cancer growth and treatments. J Theor Biol 2014; 351: 74-82. https://doi. org/10.1016/j.jtbi.2014.02.028

[26] MASAMUNE A, SATOH M, HIRABAYASHI J, KASAI K, SATOH K et al. Galectin-1 induces chemokine production and proliferation in pancreatic stellate cells. Am J Physiol Gastrointest Liver Physiol 2006; 290: G729-736. https://doi. org/10.1152/ajpgi.00511.2005

[27] BIRTOLO C, PHAM H, MORVARIDI S, CHHEDA C, GO VL et al. Cadherin-11 Is a Cell Surface Marker Up-Regulated in Activated Pancreatic Stellate Cells and Is Involved in Pancreatic Cancer Cell Migration. Am J Pathol 2017; 187: 146-155. https://doi.org/10.1016/j.ajpath.2016.09.012

[28] MOHELNIKOVA-DUCHONOVA B, BRYNYCHOVA V, OLIVERIUS M, HONSOVA E, KALA Z et al. Differences in transcript levels of ABC transporters between pancreatic adenocarcinoma and nonneoplastic tissues. Pancreas 2013; 42: 707-716. https://doi.org/10.1097/MPA.0b013e318279b861
[29] GUZMAN EA, HARMODY D, PITTS TP, VERA-DIAZ B, WINDER PL et al. Inhibition of IL-8 secretion on BxPC3 and MIA PaCa- 2 cells and induction of cytotoxicity in pancreatic cancer cells with marine natural products. Anticancer Drugs 2017; 28: 153-160. https://doi.org/10.1097/ CAD.0000000000000443

[30] PAN MR, HSU MC, LUO CW, CHEN LT, SHAN YS et al. The histone methyltransferase G9a as a therapeutic target to override gemcitabine resistance in pancreatic cancer. Oncotarget 2016; 7: 61136-61151. https://doi.org/10.18632/oncotarget.11256

[31] ZHAO W, AJANI JA, SUSHOVAN G, OCHI N, HWANG $\mathrm{R}$ et al. Galectin-3 Mediates Tumor Cell-Stroma Interactions by Activating Pancreatic Stellate Cells to Produce Cytokines via Integrin Signaling. Gastroenterology 2018; 154: 15241537.e6. https://doi.org/10.1053/j.gastro.2017.12.014

[32] CHEN L, FAN J, CHEN H, MENG Z, CHEN Z et al. The IL-8/CXCR1 axis is associated with cancer stem cell-like properties and correlates with clinical prognosis in human pancreatic cancer cases. Sci Rep 2014; 4: 5911. https://doi. org/10.1038/srep05911

[33] ANQUETIL F, SABOURI S, THIVOLET C, RODRIGUEZCALVO T, ZAPARDIEL-GONZALO J et al. Alpha cells, the main source of IL- $1 \beta$ in human pancreas. J Autoimmun 2017; 81: 68-73. https://doi.org/10.1016/j.jaut.2017.03.006

[34] AOKI H, OHNISHI H, HAMA K, ISHIJIMA T, SATOH Y et al. Autocrine loop between TGF-beta(1) and IL-1 beta through Smad3- and ERK-dependent pathways in rat pancreatic stellate cells. Am J Physiol Cell Physiol 2006; 290: C1100-C1108. https://doi.org/10.1152/ajpcell.00465.2005

[35] HE BS, PAN YQ, XU YF, ZHU C, QU LL et al. Polymorphisms in Interleukin-1B (IL-1B) and Interleukin 1 Receptor Antagonist (IL-1RN) Genes Associate with Gastric Cancer Risk in the Chinese Population. Digest Dis Sci 2011; 56: 2017-2023. https://doi.org/10.1007/s10620-010-1557-y

[36] TEKPLI X, LANDVIK NE, ANMARKUD KH, SKAUG V, HAUGEN A et al. DNA methylation at promoter regions of interleukin $1 \mathrm{~B}$, interleukin 6 , and interleukin 8 in non-small cell lung cancer. Cancer Immunol Immunother 2013; 62; 337-345. https://doi.org/10.1007/s00262-012-1340-3

[37] ELARAJ DM, WEINREICH DM, VARGHESE S, PUHLMANN M, HEWITT SM et al. The role of interleukin 1 in growth and metastasis of human cancer xenografts. Clin Cancer Res 2006; 12: 1088-1096. https://doi.org/10.1158/10780432.CCR-05-1603

[38] VORONOV E, CARMI Y, APTE RN. Role of IL-1-mediated inflammation in tumor angiogenesis. Adv Exp Med Biol 2007; 601: 265-270.

[39] WANG Z, AZMI AS, AHMAD A, BANERJEE S, WANG S et al. TW-37, a small-molecule inhibitor of Bcl-2, inhibits cell growth and induces apoptosis in pancreatic cancer: involvement of Notch-1 signaling pathway. Cancer Res 2009; 69: 2757-2765. https://doi.org/10.1158/0008-5472.CAN-08-3060

[40] XU C, WU A, ZHU H, FANG H, XU L et al. Melatonin is involved in the apoptosis and necrosis of pancreatic cancer cell line SW-1990 via modulating of Bcl-2/Bax balance. Biomed Pharmacother 2013; 67: 133-139. https://doi.org/10.1016/j. biopha.2012.10.005 
[41] SONG S, WANG B, GU S, LI X, SUN S. Expression of Beclin 1 and Bcl-2 in pancreatic neoplasms and its effect on pancreatic ductal adenocarcinoma prognosis. Oncol Lett 2017; 14: 7849-7861. https://doi.org/10.3892/ol.2017.7218

[42] KUMAR P, NING Y, POLVERINI PJ. Endothelial cells expressing Bcl-2 promote tumor metastasis by enhancing tumor angiogenesis, blood vessel leakiness and tumor invasion. Lab Invest 2008; 88: 740-749. https://doi.org/10.1038/ labinvest.2008.46

[43] LUTZ ER, WU AA, BIGELOW E, SHARMA R, MO G et al. Immunotherapy converts nonimmunogenic pancreatic tumors into immunogenic foci of immune regulation. Cancer Immunol Res 2014; 2: 616-631. https://doi. org/10.1158/2326-6066.CIR-14-0027

[44] MONTI P, LEONE BE, MARCHESI F, BALZANO G, ZERBI A et al. The CC chemokine MCP-1/CCL2 in pancreatic cancer progression: Regulation of expression and potential mechanisms of antimalignant activity. Cancer Res 2003; 63: 7451-7461.

[45] KALBASI A, KOMAR C, TOOKER GM, LIU M, LEE JW et al. Tumor-Derived CCL2 Mediates Resistance to Radiotherapy in Pancreatic Ductal Adenocarcinoma. Clin Cancer Res 2017; 23: 137-148. https://doi.org/10.1158/1078-0432. CCR-16-0870

[46] LONG KB, GLADNEY WL, TOOKER GM, GRAHAM K, FRAIETTA JA et al. IFN- $\gamma$ and CCL2 cooperate to redirect tumor-infiltrating monocytes to degrade fibrosis and enhance chemotherapy efficacy in pancreatic carcinoma. Cancer Discovery 2016; 6: 400. https://doi.org/10.1158/21598290.CD-15-1032

[47] BAYNE LJ, BEATTY GL, JHALA N, CLARK CE, RHIM $\mathrm{AD}$ et al. Tumor-Derived Granulocyte-Macrophage ColonyStimulating Factor Regulates Myeloid Inflammation and $\mathrm{T}$ Cell Immunity in Pancreatic Cancer. Cancer Cell 2012; 21 : 822-835. https://doi.org/10.1016/j.ccr.2012.04.025

[48] PYLAYEVA-GUPTA Y, LEE KE, HAJDU CH, MILLER G, BAR-SAGI D. Oncogenic Kras-Induced GM-CSF Production Promotes the Development of Pancreatic Neoplasia. Cancer Cell 2012; 21: 836-847. https://doi.org/10.1016/j. ccr.2012.04.024

[49] MACE TA, AMEEN Z, COLLINS A, WOJCIK S, MAIR M et al. Pancreatic Cancer-Associated Stellate Cells Promote Differentiation of Myeloid-Derived Suppressor Cells in a STAT3-Dependent Manner. Cancer Res 2013; 73: 30073018. https://doi.org/10.1158/0008-5472.CAN-12-4601

[50] HAN X, ZHAO J, JI Y, XU X, LOU W. Expression of CK19 and KIT in resectable pancreatic neuroendocrine tumors. Tumor Biol 2013; 34: 2881-2889. https://doi.org/10.1007/ s13277-013-0850-8

[51] ZHANG L, SMYRK TC, OLIVEIRA AM, LOHSE CM, ZHANG $S$ et al. KIT is an Independent Prognostic Marker for Pancreatic Endocrine Tumors A Finding Derived From Analysis of Islet Cell Differentiation Markers. Am J Surg Pathol 2009; 33: 1562-1569. https://doi.org/10.1097/ PAS.0b013e3181ac675b
[52] BERGMANN F, MOLDENHAUER G, HERPEL E, GAIDA MM, STROBEL $O$ et al. Expression of L1CAM, COX-2, EGFR, c-KIT and Her2/neu in anaplastic pancreatic cancer: putative therapeutic targets? Histopathology 2010; 56: 440448. https://doi.org/10.1111/j.1365-2559.2010.03499.x

[53] KNOSEL T, CHEN Y, ALTENDORF-HOFMANN A, DANIELCZOK C, FREESMEYER $M$ et al. High KIT and PDGFRA are associated with shorter patients survival in gastroenteropancreatic neuroendocrine tumors, but mutations are a rare event. J Cancer Res Clin 2012; 138: 397-403. https:// doi.org/10.1007/s00432-011-1107-9

[54] YASUDA A, SAWAI H, TAKAHASHI H, OCHI N, MATSUO Y et al. The stem cell factor/c-kit receptor pathway enhances proliferation and invasion of pancreatic cancer cells. Mol Cancer 2006; 5: 46. https://doi.org/10.1186/1476-45985-46

[55] HUANG C, LI N, LI Z, CHANG A, CHEN Y et al. Tumourderived Interleukin 35 promotes pancreatic ductal adenocarcinoma cell extravasation and metastasis by inducing ICAM1 expression. Nat Commun 2017; 8: 14035. https://doi. org/10.1038/ncomms 14035

[56] JACOBSEN M, SCHWEER D, ZIEGLER A, GABER R, SCHOCK $S$ et al. A point mutation in PTPRC is associated with the development of multiple sclerosis. Nature Genet 2000; 26: 495. https://doi.org/10.1038/82659

[57] PORCU M, KLEPPE M, GIANFELICI V, GEERDENS E, DE KEERSMAECKER $\mathrm{K}$ et al. Mutation of the receptor tyrosine phosphatase PTPRC (CD45) in T-cell acute lymphoblastic leukemia. Blood 2012; 119: 4476-4479. https://doi. org/10.1182/blood-2011-09-379958

[58] MA J, SAWAI H, MATSUO Y, OCHI N, YASUDA A et al. IGF-1 mediates PTEN suppression and enhances cell invasion and proliferation via activation of the IGF-1/Akt signaling pathway in pancreatic cancer cells. J Surg Res 2010; 160: 90-101. https://doi.org/10.1016/j.jss.2008.08.016

[59] SATO N, MATSUBAYASHI H, FUKUSHIMA N, GOGGINS M. The chemokine receptor CXCR4 is regulated by DNA methylation in pancreatic cancer. Cancer Biol Ther 2005; 4: 70-76.

[60] RYDER NM, GUHA S, HINES OJ, REBER HA, ROZENGURT E. G protein-coupled receptor signaling in human ductal pancreatic cancer cells: Neurotensin responsiveness and mitogenic stimulation. J Cell Physiol 2001; 186: 53-64. https://doi.org/10.1002/1097-4652(200101)186:1<53::AIDJCP1004>3.0.CO;2-Q

[61] RYSCHICH E, NOTZEL T, HINZ U, AUTSCHBACH F, FERGUSON J et al. Control of T-cell-mediated immune response by HLA class I in human pancreatic carcinoma. Clinical Cancer Research 2005; 11: 498-504.

[62] WALTER N, BUSCH T, SEUFFERLEIN T, SPATZ JP. Elastic moduli of living epithelial pancreatic cancer cells and their skeletonized keratin intermediate filament network. Biointerphases 2011; 6: 79-85. https://doi.org/10.1116/1.360175 


\section{Identification of key pathways and gene changes in primary pancreatic stellate cells after cross-talk with pancreatic cancer cells (BXPC-3) using bioinformatics analysise}

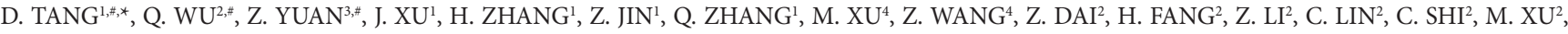
X. SUN ${ }^{2}$, D. WANG ${ }^{1, *}$

Supplemental material
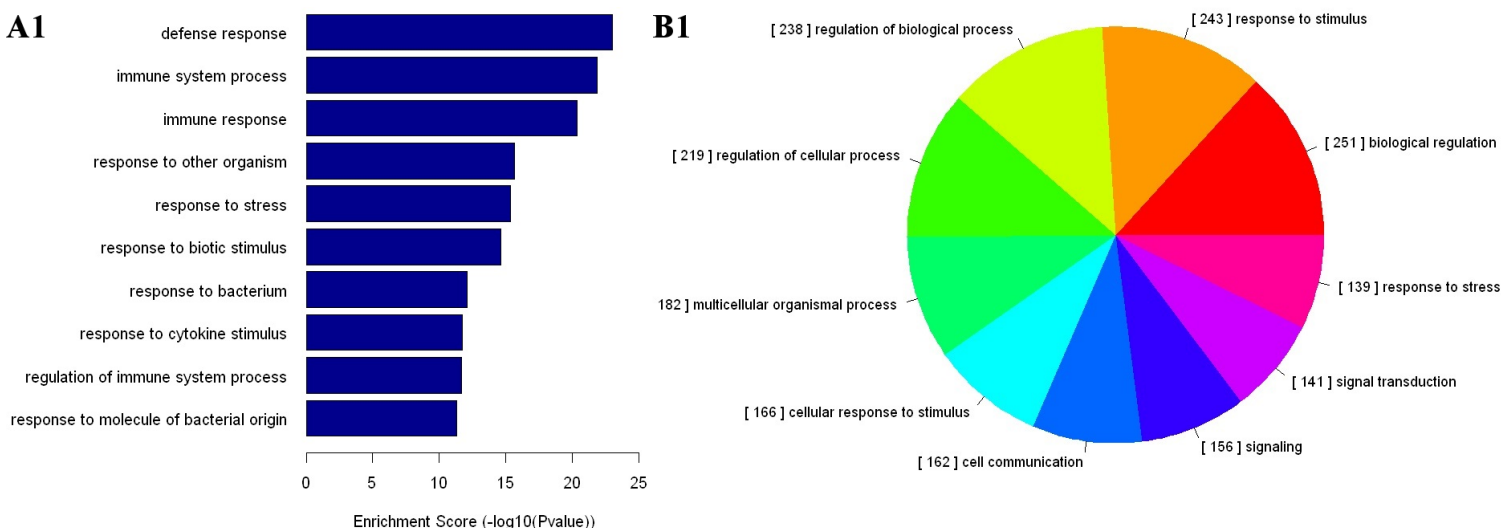

Enrichment Score (-log10(Pvalue))

A2

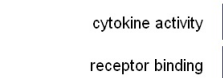

cytokine receptor binding

chemokine activity

chemokine receptor binding

growth factor activity

IgG binding

growth factor receptor binding

protein tyrosine phosphatase activity

lipid binding

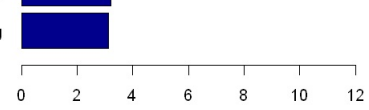

Enrichment Score (-log10(Pvalue))

A3

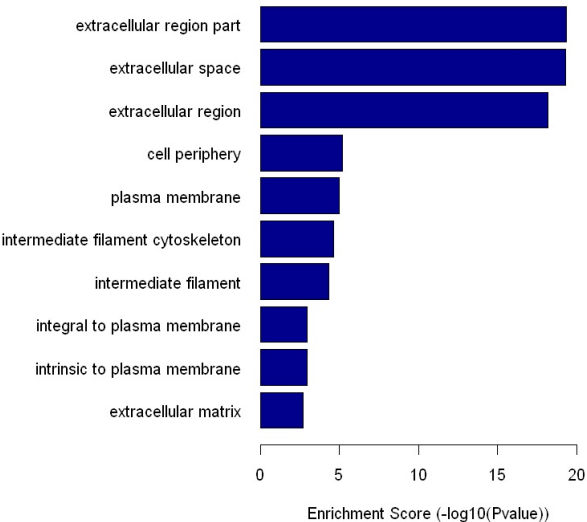

B2

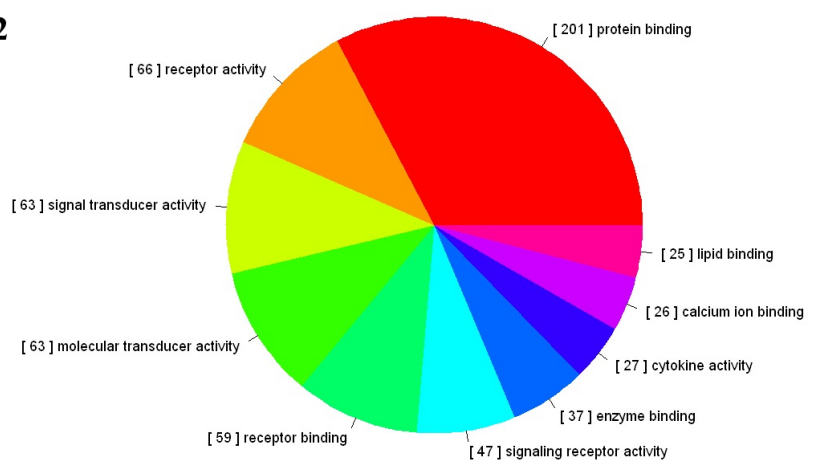

B3

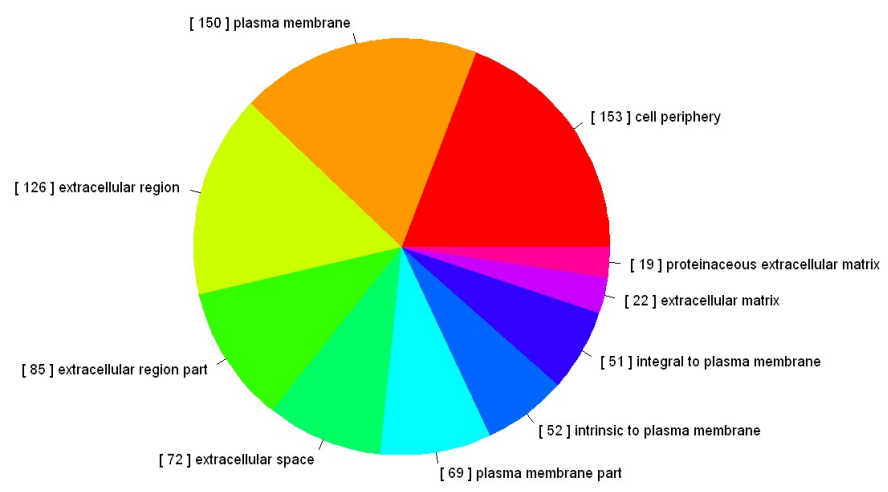

Supplementary Figure 1a. The results of GO analysis. A1-B3: GO analysis for up-regulated DEGs. A1-3: The top ten Enrichment Score value of the significant enrichment terms (biological processes, molecular function and GO cell component); B1-3: the top ten counts of the significant enrichment terms (biological processes, molecular function and GO cell component). 
C1

$$
\begin{array}{r}
\text { biological regulation } \\
\text { cytoskeleton organization } \\
\text { regulation of biological process } \\
\text { regulation of cellular process } \\
\text { cellular process } \\
\text { actin filament-based process } \\
\text { actin cytoskeleton organization } \\
\text { positive regulation of cell division }
\end{array}
$$

negative regulation of protein complex disassembly

regulation of transcription, DNA-dependent

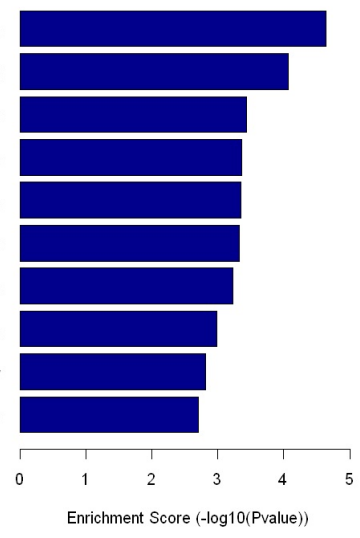

C2

phospholipid-translocating ATPase activity

protein binding

zinc ion binding

heparan sulfate proteoglycan binding

drug binding

active transmembrane transporter activity

phosphoric diester hydrolase activity

hydrolase activity, acting on acid anhydrides, catalyzing transmembrane movement of substances activating transcription factor binding

ion binding

D1

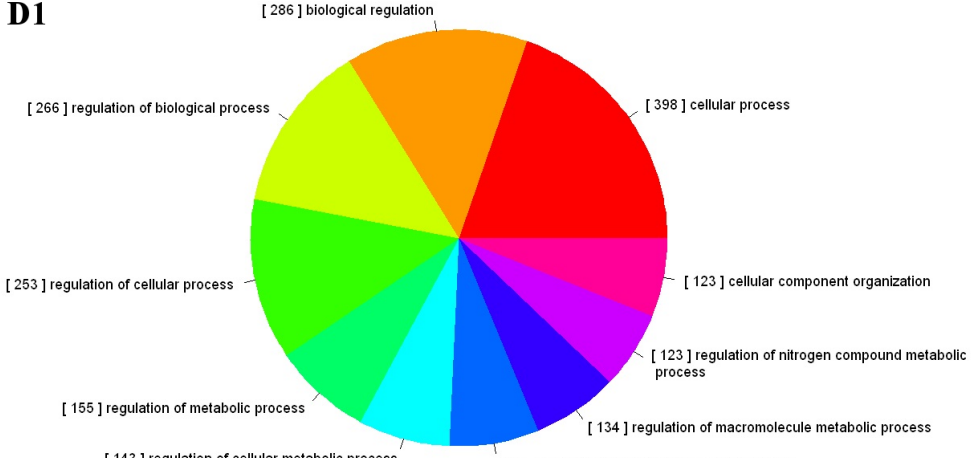

C3

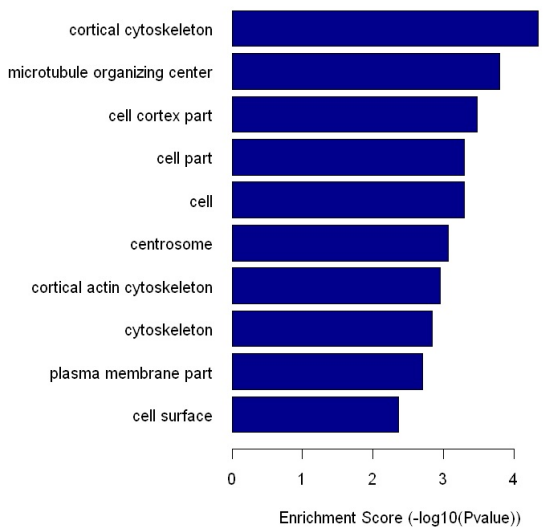

[ 143 ] regulation of cellular metabolic process

D2

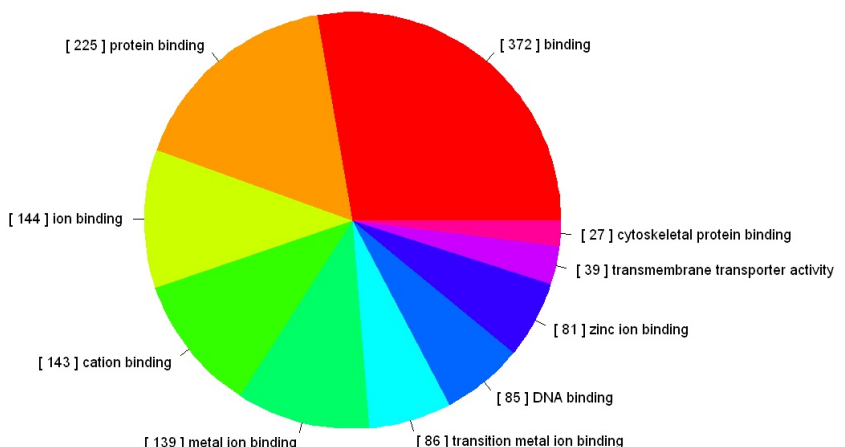

[ 139 ] metal ion binding

[ 86 ] transition metal lon binding

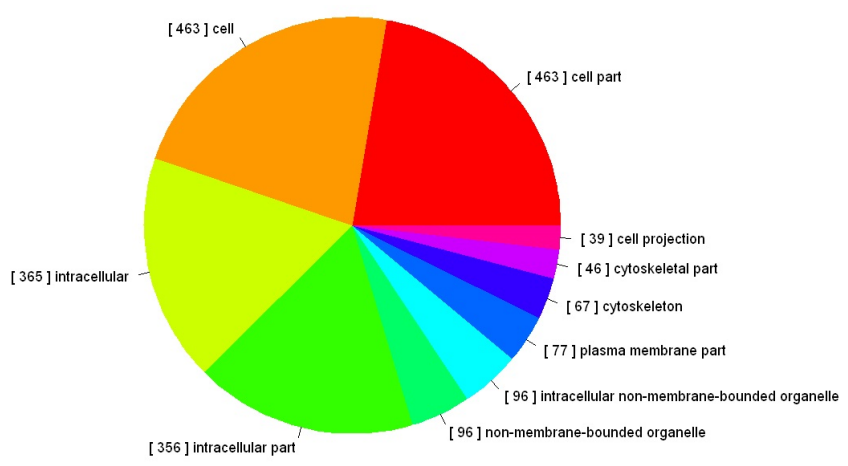

D3
[141] regulation of primary metabolic process

(a)

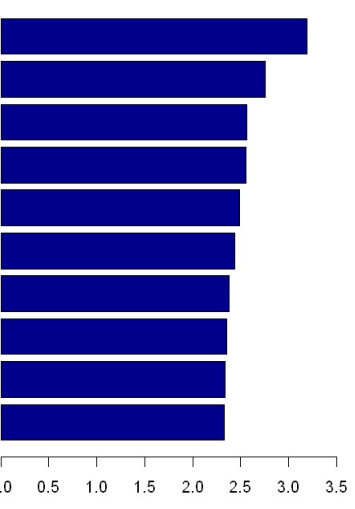

Enrichment Score $(-\log 10$ (Pvalue) $)$

Enrichment Score (-log10(Pvalue))

Supplementary Figure 1a. The results of GO analysis. C1-D3: GO analysis for down-regulated DEGs; C1-3: The top ten Enrichment Score value of the significant enrichment terms (biological processes, molecular function and GO cell component); D1-3: the top ten counts of the significant enrichment terms (biological processes, molecular function and GO cell component). 


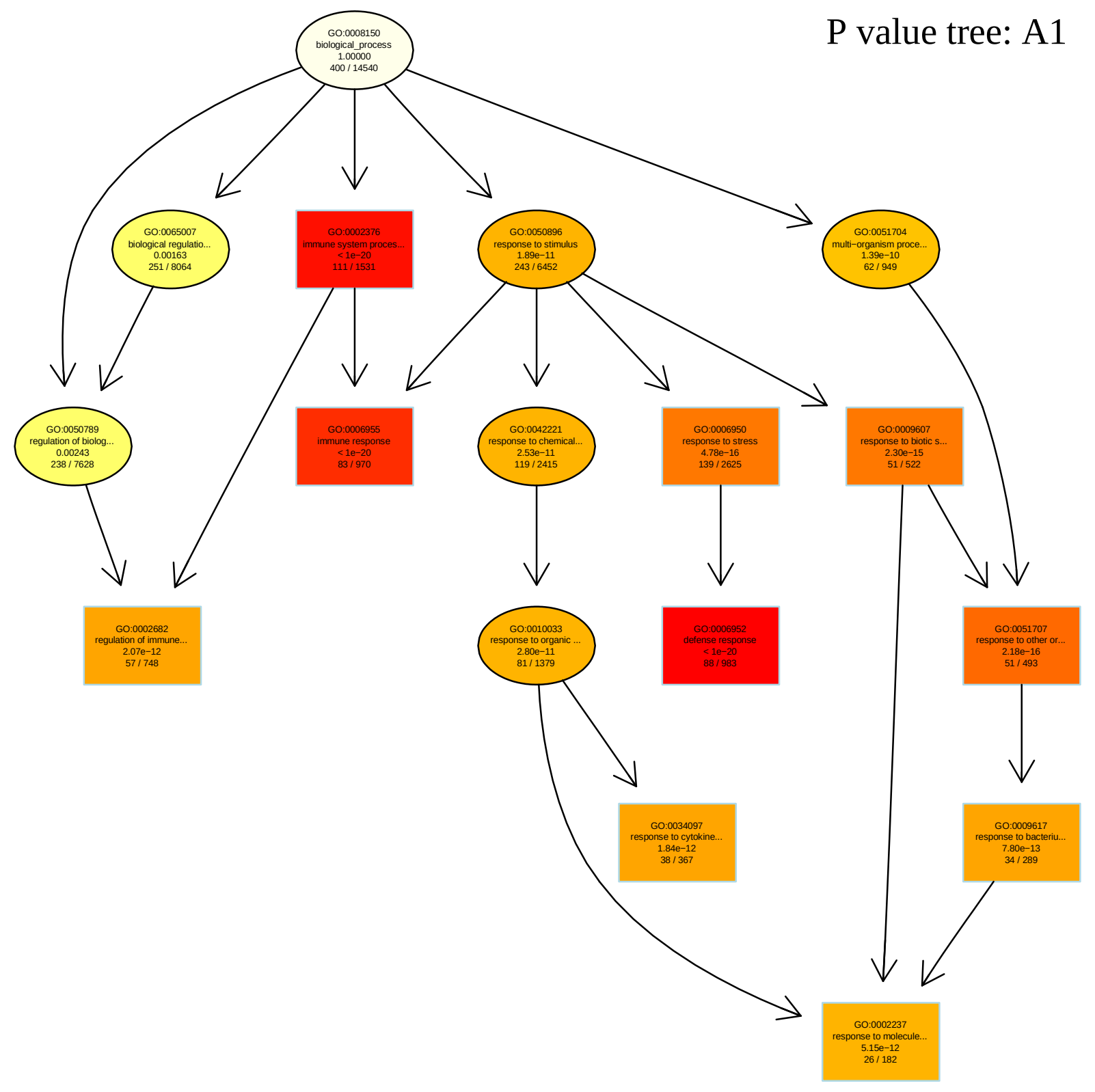

Supplementary Figure 1b. p-value tree of biological processes, molecular function and GO cell component for A1-3 charts and C1-3 charts in Suppl. Figure 1a. 


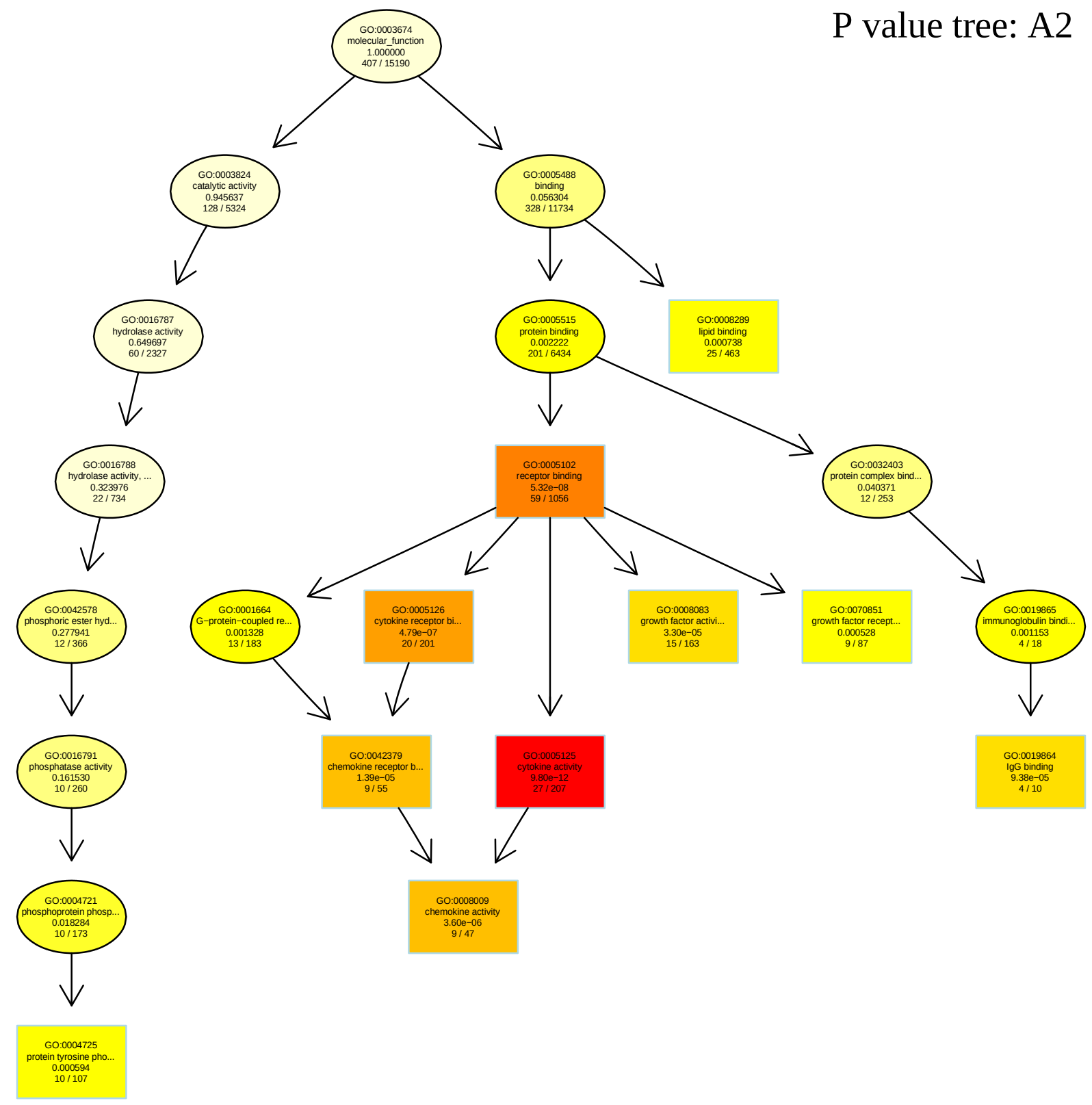




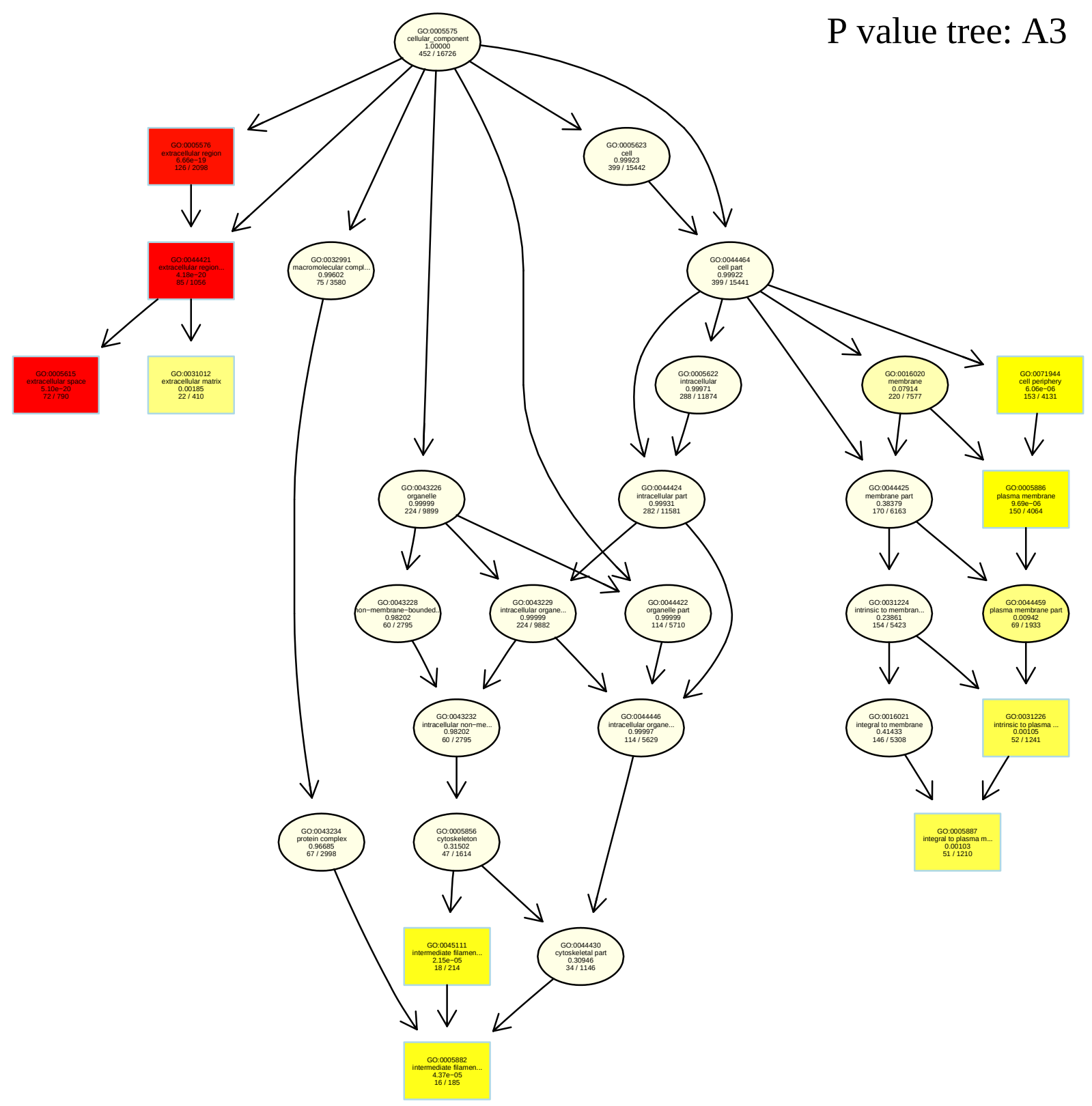




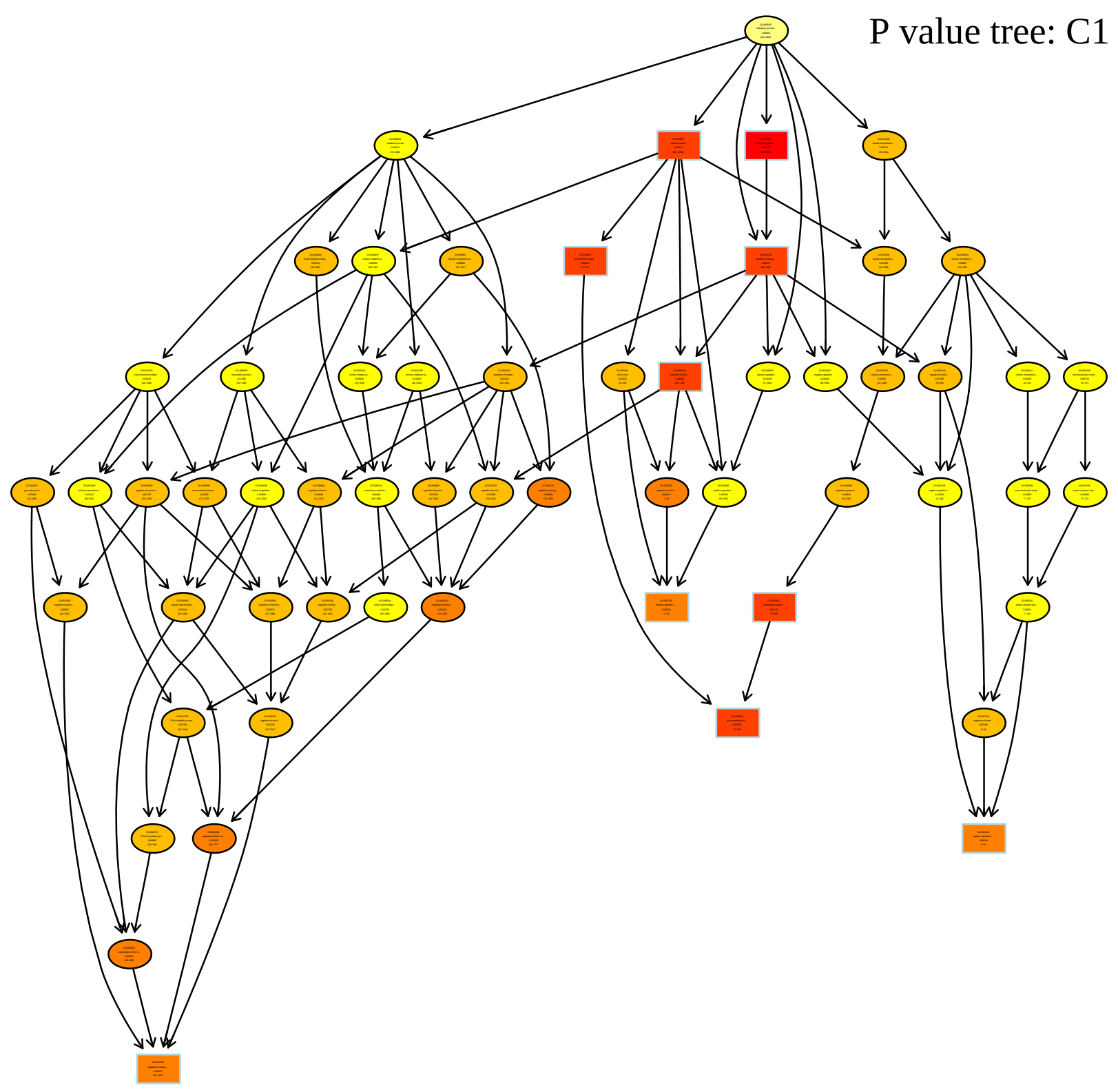




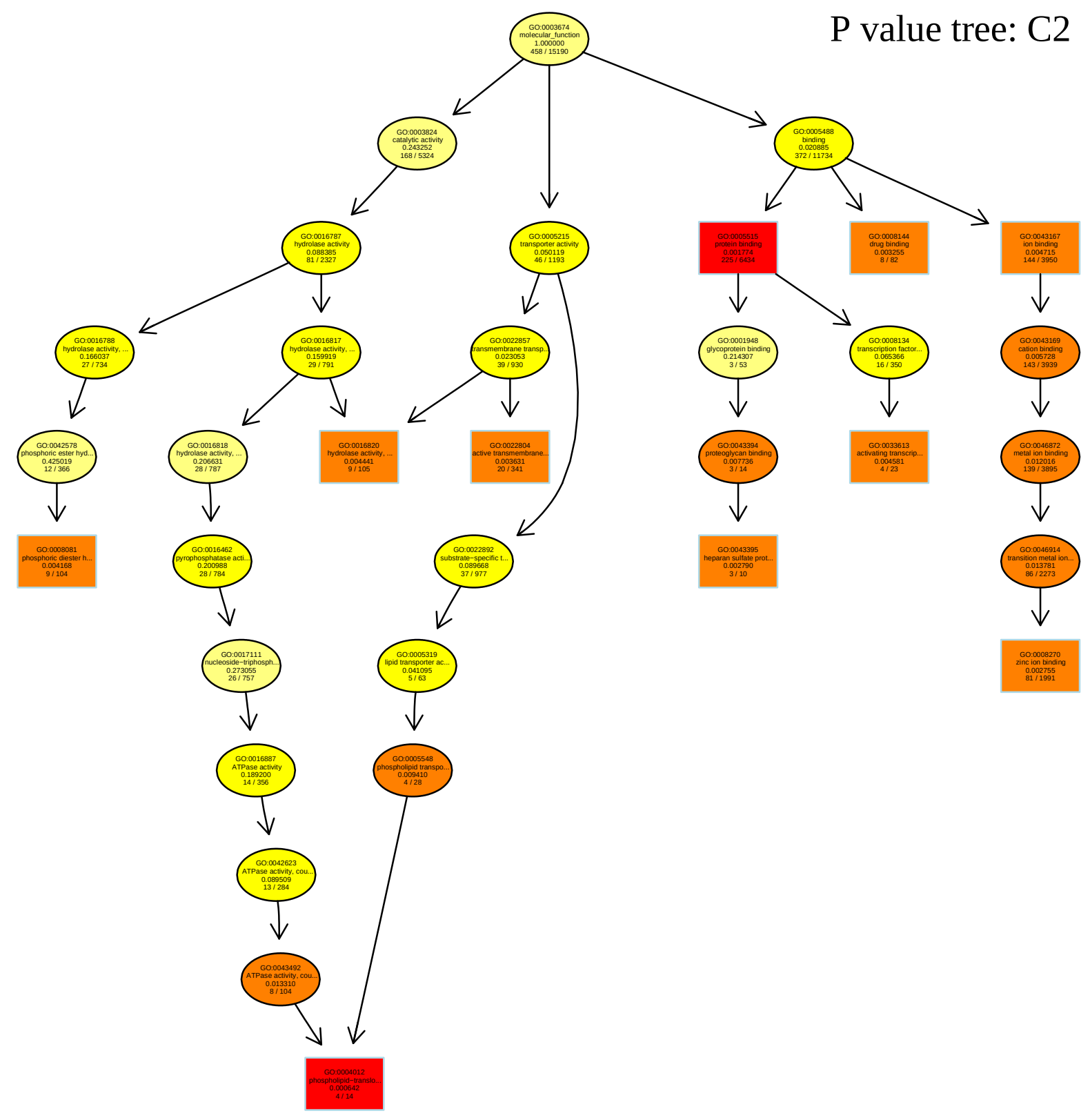




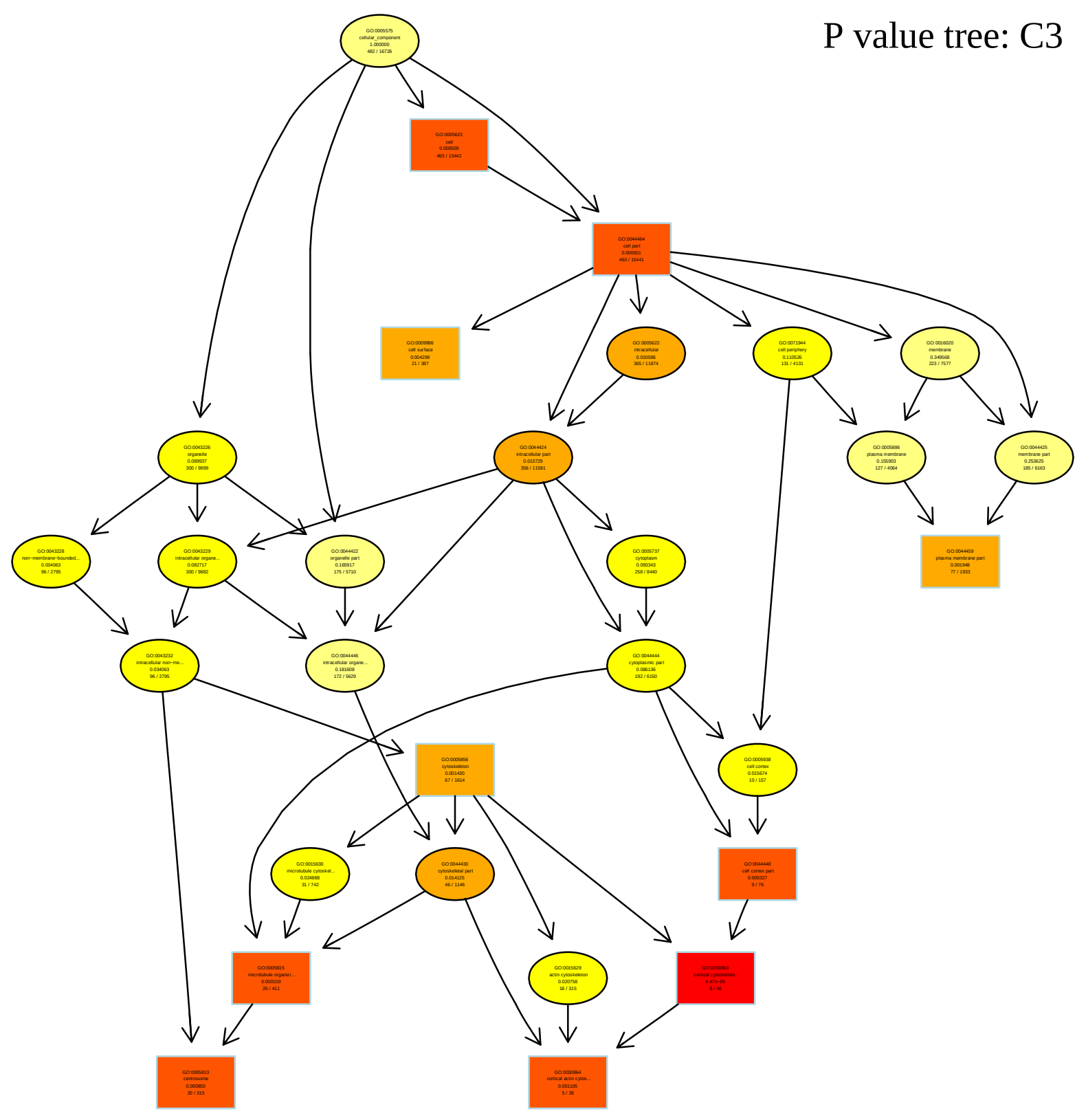

